\title{
Crisis y cambios estructurales en el sector bancario español: Una comparación con otros sistemas financieros
}

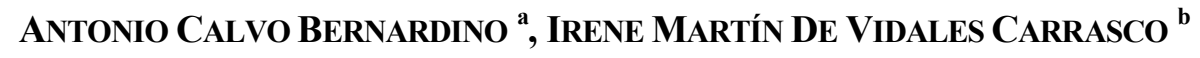 \\ a Universidad CEU SAN PABLO, Facultad de CC.EE., c/ Julión Romea, 23, 28003 Madrid, España. \\ E-mail: acalvo@ceu.es \\ ${ }^{b}$ Universidad de Castilla-La Mancha, Facultad Ciencias Jurídicas y Sociales, c/ Cobertizo San Pedro \\ Martir, s/n, 45071 Toledo,España.E-mail: Irene.MartinVidales@uclm.es
}

\begin{abstract}
RESUMEN
La grave crisis económica que acompañó a la crisis financiera inicial, cuyo origen se establece en el sector de la vivienda en Estados Unidos, y las posteriores tensiones en los mercados de deuda soberana europea, generaron importantes problemas de estabilidad y de solvencia en el sector bancario español. Este entorno de profunda inestabilidad económica y financiera constituye el punto de partida de este trabajo, que tiene como objetivo prioritario, en primer lugar, realizar un análisis de las reformas financieras adoptadas por las autoridades españolas desde finales de 2008, momento en el que se implementaron medidas a corto o medio plazo para hacer frente a las consecuencias más inmediatas de la crisis, hasta la finalización del programa de asistencia financiera; y, en segundo, comparar los resultados alcanzados con los correspondientes a otros sistemas bancarios que también han recibido apoyos públicos.
\end{abstract}

Palabras clave: Crisis económica y financiera, reforma bancaria y financiera, rescate bancario, España.

\section{The Crisis and Structural Changes to the Spanish Banking Sector: A Comparison with other Financing Systems}

\begin{abstract}
The grave economic crisis that accompanied the initial financing crisis, whose origin is established in the housing sector in the United States of America, and the following tensions in the European sovereign debt markets, generated important stability and solvency problems in the Spanish banking sector. This environment of profound economic and financing instability constitutes the starting point of this work, that has as its main objective, in the first place, to realize an analysis of the financing reforms adopted by the Spanish authorities since the end of 2008, the moment in which short or medium range steps were implemented to face up to the more immediate consequences of the crisis, until the end of the financing assistance program, and, in the second place, to compare the results obtained with those corresponding to other banking systems that have also received public support.
\end{abstract}

Keywords: Economic and Financial Crisis, Banking and Financial Reform, Banking Bailout, Spain.

Clasificación JEL: G15, G18, G21

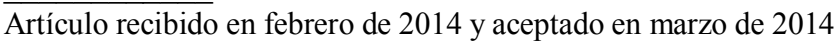

Artículo disponible en versión electrónica en la página www.revista-eea.net, ref. ə-32205 


\section{INTRODUCCIÓN}

La grave crisis financiera, iniciada en los Estados Unidos, y trasladada a Europa, ha generado cambios sustanciales en la estructura de los sistemas financieros más afectados por la misma, en los que hemos asistido a procesos de consolidación y a reformas legislativas para su adaptación al nuevo contexto.

En el caso español, en concreto, los cambios han sido muy intensos, y se han centrado en tratar de dotar de una mayor fortaleza a las entidades bancarias a través de intensas y profundas reestructuraciones, que han llevado a una reducción en su número y en su presencia territorial, y a la exigencia de unos mayores recursos propios que las posibiliten resistir con firmeza los embates de posibles crisis futuras y de ganar importancia y confianza en el contexto de los mercados exteriores.

Teniendo en cuenta lo anterior, el presente artículo persigue un doble objetivo: por una parte, analizar las reformas financieras emprendidas por nuestras autoridades desde el año 2008, momento en el que se deja sentir con intensidad los efectos de la crisis, y se produce un cambio en el comportamiento estratégico de nuestras entidades, a veces forzado, por la situación de crisis en las que se encuentran inmersas algunas de ellas, y otras, de manera pseudovoluntaria, pues, sin las perentorias necesidades de saneamiento, la reestructuración se ha llevado a cabo, orientada por las propias autoridades, por propia iniciativa.

Por otra parte, sin entrar en los cambios legislativos emprendidos en otros países, tratar de vislumbrar si esa tendencia observada en España también ha sido seguida por otros países cuyos sistemas financieros han sido objeto de ayudas públicas para su saneamiento. Todo ello nos permitirá comprobar, de modo comparado, los principales cambios en algunas de las magnitudes de sus sistemas bancarios, y tratar de determinar las diferencias y similitudes que presentan con los ajustes producidos en el de nuestro país.

Para conseguir estos objetivos, hemos dividido el artículo en los siguientes apartados. Tras esta introducción, en el segundo se hace una referencia al tratamiento de la crisis financiera en otros países que han recibido ayudas para su sector financiero; en concreto, dentro de la zona euro, Alemania, Irlanda, Portugal y Chipre, y fuera de ella, Estados Unidos e Islandia. En el tercer apartado se analizan en profundidad las reformas emprendidas desde 2008 por nuestras autoridades en el sector, distinguiendo entre las aplicadas antes de la obtención de las ayudas internacionales para el rescate bancario y las puestas en marcha como consecuencia de los compromisos asumidos para la obtención de los fondos para el saneamiento.

En el cuarto apartado, a partir de diversos datos relativos a la actividad bancaria, se analiza el impacto de la crisis y las acciones emprendidas por las enti- 
dades bancarias de esos países, lo que nos permitirá comparar su evolución con las magnitudes correspondientes a las entidades españolas.

Finalmente, terminamos el artículo destacando las principales conclusiones obtenidas del análisis realizado.

\section{CRISIS FINANCIERA, TRATAMIENTO INTERNACIONAL Y AYUDAS PÚBLICAS}

Aunque el origen de la crisis financiera, que ha afectado a un gran número de países desarrollados, se suele poner en las denominadas hipotecas subprime en Estados Unidos, un análisis más profundo de la misma debe llevar a considerar una diversidad de razones que la han alimentado (Servicio de Estudios de La Caixa, 2008) ${ }^{1}$, encontrándose su núcleo en los comportamientos de todos los agentes económicos implicados en la actividad financiera, desde las instituciones financieras y las personas que las integran, llevando a cabo actuaciones en demasía arriesgadas, buscando los beneficios a corto plazo sin valorar los efectos que originan esas decisiones sobre la estabilidad de las entidades a plazos mayores; a los bancos centrales, que con políticas monetarias expansivas han mantenidos unos tipos de interés artificialmente bajos y una gran liquidez, fomentando un crédito excesivo y la burbuja económica y financiera; a los organismos reguladores, que no han sido capaces de establecer y adaptar, unos principios de control y de supervisión que hayan evitado, o al menos minimizado, el impacto de la crisis; a las agencias de calificación, por no haber sido capaces de valorar adecuadamente los riesgos de los nuevos productos financieros, ofreciendo una información engañosa a los inversores, y poniendo además en entredicho su independencia respecto a las entidades cuyas emisiones califican; y a los propios inversores, que se han hecho partícipes de todos esos errores, llevando su endeudamiento a unos niveles insostenibles (Toribio, 2010; Calvo y Mingorance, 2012).

Sin embargo, el impacto de la crisis se dejó sentir en los países en distintos momentos del tiempo, lo que les llevó a responder de forma muy diferente a los problemas ocasionados en sus sistemas bancarios. Así, mientras que algunos, como Estados Unidos o Reino Unido, respondieron de forma rápida; otros, en los que el impacto de esta crisis financiera no fue tan rápido, tuvieron un cierto margen de maniobra para diseñar las medidas más adecuadas que permitieran atajar los problemas originados sobre sus entidades financieras (Calvo y Martín de Vidales, 2014).

\footnotetext{
${ }^{1}$ Tales como la burbuja especulativa en los activos inmobiliarios, la ausencia de regulación efectiva de algunas de las actividades bancarias, el diseño de incentivos vinculados a los beneficios a corto plazo de las entidades y el excesivo apalancamiento del sector financiero.
} 
En Estados Unidos, tras unas primeras reacciones individuales, como en el caso de Bearn Stern, el 3 de octubre de 2008 el Congreso aprobó el Trouble Relief Asset Program (TARP), consistente en la compra por el Tesoro de activos con problemas de valoración, para lograr un cierto saneamiento de los balances de las entidades implicadas. Sin embargo, este Programa fue modificado apenas diez días después (14 de octubre) con el fin de permitir las inyecciones de capital y de diseñar un programa de garantías para las emisiones de deuda bancaria respaldadas por el Fondo de Garantía de Depósitos.

Además, a finales de ese año y principios de 2009, dentro de una estrategia más global, se aprobó un nuevo plan de rescate, en el que se incluyeron, entre otras, la creación de varios fondos para la adquisición de activos problemáticos, con una capacidad de compra de hasta 500 mil millones de dólares y una expansión potencial hasta un billón, si hubiese sido necesario, y así darlos salida de los balances bancarios.

A lo largo de 2009, el proceso de normalización y de recuperación de la confianza en el sector financiero estadounidense hizo que la mayoría de las entidades lograran devolver las ayudas públicas recibidas en el marco del TARP y pudieron ir retirándose los apoyos concedidos de forma ordenada, selectiva y a ritmos diferenciados por segmentos de mercado. En cualquier caso, todos los apoyos globales concedidos al sistema financiero norteamericano (no sólo las ayudas establecidas) alcanzaron el 5,1\% del PIB.

Esta primera oleada de la crisis financiera incidió severamente en la rentabilidad de los bancos, no sólo norteamericanos o británicos, sino también de otros países de la zona euro (Alemania, Holanda, Bélgica, etc.), sumándose éstos a la aplicación de medidas de inyecciones públicas de capital en diversas entidades y a la concesión de programas de avales para la emisión de valores de renta fija, desarrollando incluso planes de adquisición y protección de activos dañados.

Sin embargo, la reacción de otros países fue algo más tardía. Dentro de la zona euro, en Alemania, la intervención de las autoridades se centró en evitar la quiebra de numerosos bancos regionales, así como la nacionalización de alguna entidad, lo que supuso en total una ayuda nacional de más de 300 mil millones de euros, equivalente al 12,7\% del PIB alemán en 2008 (Deutsche Bundesbank, 2009); en Irlanda, en cambio, se dispuso la transferencia de una parte de los activos dañados a una Agencia nacional, o la petición de una ayuda formal para el conjunto de la economía, que se tradujo en un programa, en el que uno de los objetivos era el refuerzo inmediato y la revisión global del sistema bancario ${ }^{2}$.

\footnotetext{
${ }^{2}$ Irlanda solicitó el 21 de octubre de 2010 oficialmente ayuda financiera a la UE y al FMI. El programa abierto también contemplaba la realización de un fuerte ajuste presupuestario y la aplicación de medidas impulsoras del crecimiento económico, en especial en el mercado de trabajo, que supuso una ayuda total de hasta 85 mil millones de euros, repartidos entre el Fondo Europeo de Estabilidad Financiera (FEEF), el Mecanismo Europeo de Estabilidad Financiera
} 
Similares objetivos se plantearon en el Programa abierto en mayo de 2011 a Portugal, y en abril de 2013 a Chipre. En cuanto a Portugal, con un paquete de financiación de 78 mil millones de euros, repartido entre el FEEF, el MEEF y el FMI a partes iguales, el Programa establecía, en concreto para su sistema financiero, la necesidad de adoptar una estrategia basada en la recapitalización y en el desapalancamiento, empleando mecanismos de mercado respaldados por mecanismos de protección. Finalmente, dentro de la zona euro, Chipre tiene aprobado, para el período 2013-2016, un paquete financiero de hasta $10 \mathrm{mil}$ millones de euros, de los que el Mecanismo Europeo de Estabilidad (MEDE) se haría cargo de 9 mil millones y los mil restantes el FMI. Todo ello para, entre otros objetivos económicos, restablecer la solidez de su sector bancario y la confianza de los depositantes, haciendo una profunda reestructuración de las entidades financieras, reduciendo su tamaño, aumentando la supervisión y resolviendo las carencias de capital previstas ${ }^{3}$.

Por su parte, en Islandia, la quiebra de Lehman Brothers supuso el colapso de la corona, de los mercados financieros y de los tres mayores bancos comerciales del país (Glitnir, Landsbanki y Kaupthing), que por volumen de activos canalizados representaban casi la totalidad de su sistema financiero, y obligaron al gobierno a adoptar un severo ajuste y a ponerse en manos del Fondo Monetario Internacional a fin de salvar la economía ${ }^{4}$.

Aparte de la puesta en marcha de medidas económicas, centradas en la aplicación de programas de consolidación fiscal, solicitar la entrada en la UE en julio de 2009 y fijar controles de cambios y de capitales, las autoridades islandesas aprobaron una legislación de emergencia que concedía a la Autoridad de Supervisión Financiera de Islandia facultad para hacerse cargo de las operaciones domésticas de los tres principales bancos.

\section{REFORMAS EN EL SISTEMA FINANCIERO ESPAÑOL}

\subsection{Actuaciones antes del rescate bancario (noviembre de 2008-mayo de 2012)}

En el caso de España, las medidas financieras adoptadas en una primera fase, con un cierto carácter a corto o medio plazo para hacer frente a las consecuen-

(MEEF), contribuciones bilaterales del Reino Unido, Suecia y Dinamarca y el FMI, que se añaden a los casi 65 mil millones de ayudas públicas internas. Este programa se cerró de forma definitiva a finales de 2013. Las ayudas obtenidas a nivel nacional supusieron casi un $40 \%$ del PIB irlandés de 2010 y las internacionales más del 54\%.

${ }^{3}$ Además del contenido detallado de cada uno de los programas de ayudas a los sistemas bancarios de los países analizados, para un seguimiento del proceso de financiación y de saneamiento de los mismos, puede verse Unión Europea (2013).

${ }^{4}$ La inyección de liquidez del FMI en el sistema financiero islandés ascendió a un total de 2.100 millones de dólares, mientras que sus vecinos nórdicos (Noruega, Suecia, Finlandia y Dinamarca) aportaron 2.500 millones de dólares más en préstamos y swaps de divisas. 
cias más inmediatas de la crisis financiera, respondían a los principios y directrices marcados por la Unión Europea y por la Cumbre del G-20 celebrada en Washington el 15 de noviembre de 2008, para asegurar el correcto funcionamiento del mercado interior.

En primer lugar, en el marco del Plan Español para el Estímulo de la Economía y el Empleo, o, en su forma abreviada, Plan E (noviembre de 2008), para impulsar la actividad económica, movilizando grandes cantidades de dinero público ${ }^{5}$, el Gobierno articuló varias medidas de apoyo al sistema financiero $^{6}$ :

- La creación de un Fondo de Adquisición de Activos Financieros de alta calidad (por un importe de 30.000 millones de euros ampliable hasta 50.000 millones), instrumentado a través de subastas ante las entidades interesadas, con la finalidad de apoyar la oferta de crédito a la actividad productiva de las empresas y a los ahorradores ${ }^{7}$.

- El reforzamiento de la protección de los depositantes e inversores con el aumento de los importes máximos garantizados por los entonces existentes Fondos de Garantía de Depósitos (desde los 20.000 hasta los 100.000 euros por depositante y cualesquiera que sean el número y clase de depósitos).

- El otorgamiento de avales del Estado para las nuevas emisiones de renta fija de las entidades de crédito en España hasta el 31 de diciembre de 2009.

- El establecimiento de un mecanismo de autorización para poder realizar una posible recapitalización de las entidades financieras (aunque nunca se llegó a emplear).

En un principio, la capacidad de resistencia del sistema financiero español, tradicionalmente sujeto a una regulación y supervisión basadas en una aplicación prudente y rigurosa de los estándares internacionales, fue notable, situándole en una posición muy favorable en términos de rentabilidad, eficiencia,

\footnotetext{
${ }^{5}$ La primera parte del Plan E inyectó 7.836 millones de euros y la segunda hasta 5.000 millones más. Estos fondos fueron repartidos entre las diferentes administraciones, siendo los ayuntamientos los organismos que decidirían en qué obras públicas se invertiría este dinero. A estas actuaciones siguieron otras, ya que este Plan fue prolongado bajo el nombre de Plan de Economía Sostenible (Fondo Estatal para el Empleo y la Sostenibilidad Local), que en total elevaron el montante del Plan E a más de 50.000 millones de euros.

${ }^{6}$ El Plan E constaba de cuatro ejes fundamentales de actuación: medidas de apoyo a empresas y familias; de fomento del empleo; medidas financieras y presupuestarias; $y$, por último, medidas de modernización de la economía.

${ }^{7}$ Este Fondo de Adquisición de Activos Financieros se liquidó en junio de 2012 con un beneficio de 650 millones de euros.
} 
volumen de provisiones y niveles de capital respecto a los de las grandes economías avanzadas, especialmente las de nuestro entorno europeo.

Sin embargo, la duración, intensidad y rápida extensión de la crisis financiera a nivel internacional y, sobre todo, la fuerte caída de la actividad económica provocada por la misma, obligaron a una contracción en el volumen de negocio y a la racionalización de los gastos de explotación de las entidades de crédito españolas, poniendo de manifiesto un importante exceso de capacidad y las dudas sobre la viabilidad futura de algunas de ellas, debido a la interacción de la persistencia de restricciones de liquidez y de dificultades de acceso a la financiación de mercado con el deterioro relativo de sus activos, especialmente de aquellos relacionados con la exposición al sector de promoción inmobiliaria. Todos estos problemas exigieron, finalmente, en el ámbito interno, una reducción en el número de oficinas y sucursales bancarias, $\mathrm{y}$, en el ámbito externo, una reestructuración ordenada de entidades, incluyendo la posibilidad de fusiones entre las mismas.

En este sentido, la posibilidad de que conjuntamente los problemas de viabilidad de algunas entidades pudieran generar un potencial riesgo sistémico ${ }^{8}$, llevó al Gobierno a aprobar el Real Decreto-Ley 9/2009, de 26 de junio, en el que se diseñaron algunos mecanismos para promover una reestructuración ordenada del sistema bancario, con el objetivo de mantener la confianza en el sistema financiero nacional y de incrementar su fortaleza y solvencia, de manera que las entidades que subsistan sean sólidas y puedan proveer crédito con normalidad.

Así, el modelo propuesto, con carácter transitorio en función de la evolución de la crisis económica y financiera, trataba, una vez agotadas las soluciones privadas y minimizando el coste para el contribuyente cuando fuera necesario utilizar fondos públicos, de dar respuesta a las necesidades concretas de cada entidad con dificultades, favoreciendo, además, la asunción de responsabilidad de los accionistas y gestores, la transparencia del proceso de recapitalización y la protección de los depositantes. Para conseguir este objetivo, este modelo se articuló en torno a los tres Fondos de Garantía de Depósitos ${ }^{9}$ y a la utilización

\footnotetext{
${ }^{8}$ Las entidades sistémicas son aquellas que debido a su tamaño, su grado de interconexión con las demás entidades o la falta de sustitución de sus servicios o actividades, suponen un riesgo global, ya que sus caídas pueden afectar al sistema financiero en su conjunto.

${ }^{9}$ Hasta el año 2011 existían en España tres Fondos diferentes: uno para los bancos (Fondo de Garantía de Depósitos en Establecimientos Bancarios, FGDEB), otro para las cajas de ahorro (Fondo de Garantía de Depósitos en Cajas de Ahorro, FGDCA) y otro para las cooperativas de crédito (Fondo de Garantía de Depósitos en Cooperativas de Crédito, FGDCC). No obstante, con la aprobación del Real Decreto-Ley 16/2011, de 14 de octubre, todos estos fondos se unificaron mediante la creación del Fondo de Garantía de Depósitos de Entidades de Crédito (FGDEC).
} 
de una nueva institución creada al efecto, el Fondo de Reestructuración Ordenada Bancaria (FROB).

Posteriormente, dada la función esencial que desempeñan las cajas de ahorros en nuestro sistema financiero y, en general, en el ámbito económico y social, al fomentar el ahorro, la movilización de los recursos, el acceso al crédito de familias y empresas y el interés general, a través del cumplimiento de su labor social, se aprobó el Real Decreto-Ley 11/2010, de 9 de julio, que contenía dos líneas básicas de actuación: en primer lugar, la reforma del régimen jurídico de estas entidades, buscando un menor peso de los cargos de representación pública en su gobierno corporativo y, por tanto, una mayor profesionalización de los miembros de sus órganos de gobierno; $y$, en segundo lugar, el refuerzo de su capacidad para atraer capital exterior, debido a la limitación intrínseca que poseen las cajas para generar recursos propios de máxima calidad (core capital) por métodos diferentes a la capitalización de beneficios, pues el único instrumento disponible, las cuotas participativas, por su escasa liquidez y al no contar con derechos de voto, generaron importantes dudas sobre el atractivo que pudieran tener para los inversores, lo que impidió su desarrollo.

Así pues, estos dos factores de carácter estructural (naturaleza jurídica compleja y dificultad para obtener recursos propios) definían una coyuntura muy desfavorable para el sector de las cajas de ahorros españolas, que hizo necesaria una transformación relevante de su estructura, que se concretó, en un primer momento, en movimientos societarios que tenían como principal objetivo ganar solidez y mejorar la eficiencia, como un medio imprescindible para favorecer su posición competitiva y su credibilidad en los mercados, a través del incremento del tamaño medio de las entidades o grupos y del aprovechamiento de sinergias $\mathrm{y}$, posteriormente, en la introducción, a través de la citada reforma legal de 9 de julio de 2010, de dos nuevas alternativas organizativas que permitieran fortalecer, asimismo, su modelo de negocio: el ejercicio indirecto de toda su actividad financiera mediante un banco controlado por la caja, al tener al menos el 50\% de su capital, o bien su transformación en una fundación de carácter especial, conservando la obra social y traspasando todo su negocio financiero a un banco.

Finalmente, siguiendo la tendencia de otros países de nuestro entorno europeo, el Real Decreto-Ley 11/2010 contempla, además, una serie de ajustes para dotar de mayor consistencia y seguridad jurídica a los, creados al amparo de la nueva normativa, SIP (Sistemas Institucionales de Protección) ${ }^{10}$, puesto que refuerza aún más el compromiso de permanencia y estabilidad de las entidades integradas, buscando nuevamente un aumento de la eficiencia del sector de las

\footnotetext{
${ }^{10}$ Se trata de una fórmula de cooperación que permite compartir la liquidez y el riesgo de crédito entre entidades. Para ello, es necesario un sistema común de información, contabilidad y auditoría que facilite la evaluación común del riesgo que asume cada entidad y que, compartido, reduce los costes de cada una de ellas.
} 
cajas de ahorros y una mejora de su acceso a la financiación en los mercados de capitales.

Durante los primeros meses de 2011, ante la mayor incertidumbre generada por una nueva fase de la crisis, ahora por la deuda soberana de la Eurozona, el Gobierno español, con el fin de facilitar el acceso a la financiación de las entidades de crédito, salvaguardar la estabilidad del sistema financiero, fomentar su reestructuración y eficiencia, y velar, en última instancia, por la adecuada canalización del crédito hacia la economía real, aprobó el Real Decreto-Ley 2/2011, de 18 de febrero, que respondió a un doble objetivo: por un lado, reforzar el nivel de solvencia de todas las entidades, mediante el incremento de los requerimientos de capital principal (el 8\% de los activos ponderados por riesgo con carácter general, que se eleva al 10\% para aquellos grupos financieros que no hayan colocado al menos un $20 \%$ de su capital entre inversores terceros y tengan un porcentaje de financiación mayorista superior al 20\%); y, por otro lado, acelerar la fase final de los procesos de reestructuración de las entidades, a través del marco indispensable creado por el Real Decreto-Ley 11/2010.

Todas estas medidas, encaminadas básicamente a eliminar las debilidades coyunturales de las entidades de crédito españolas en el contexto de la escasa liquidez existente desde el inicio de la crisis, se mostraron claramente insuficientes, lo que llevó al nuevo y actual gobierno de nuestro país a aprobar una normativa adicional, el Real Decreto-Ley 2/2012, de 3 de febrero, de saneamiento del sector financiero, que comienza por reconocer que a los cuatro años de iniciarse la crisis financiera internacional todavía persisten los problemas de confianza en él y las restricciones crediticias, a los que se añaden un fuerte deterioro de los activos relacionados con el sector inmobiliario (activos tóxicos) de nuestras entidades bancarias y un exceso de capacidad en ellas que dificulta considerablemente su eficiencia y competitividad.

Así pues, esta normativa contiene una estrategia integral de reforma financiera que pretendió, en última instancia, profundizar en la recuperación de la credibilidad, la confianza y la fortaleza del sistema financiero español (Cuervo y otros, 2012), basándose en: el saneamiento de los balances de las entidades de crédito; la creación de incentivos que propiciaran un ajuste adecuado y eficiente de los excesos de capacidad instalada; el fortalecimiento de la gobernanza de las entidades resultantes de los procesos de integración; y garantizar en la medida de lo posible que los costes del saneamiento no recayeran sobre el sector público sino sobre el sistema financiero.

Para lograr estos objetivos, las medidas más relevantes aplicadas fueron: la exigencia de nuevos requerimientos de provisiones y de capital principal adi- 
cionales $^{11}$; modificaciones en el FROB, para facilitar su papel en la gestión de la crisis económica y financiera; nuevos cambios en el régimen jurídico de las cajas de ahorros, relativos, fundamentalmente, a la simplificación de su estructura organizativa y a los requisitos operativos para las que ejercen su actividad de forma indirecta; y limitaciones a las retribuciones de los directivos y administradores de las entidades de crédito que hayan precisado o necesiten en el futuro apoyo financiero público a través del FROB.

Todas estas medidas adoptadas en el sistema financiero español desde finales de 2008, que aparecen sintetizadas en la Tabla 1, no evitaron, sin embargo, que nuestras autoridades tuvieran que solicitar a las europeas ayudas para el rescate del sistema bancario.

\section{Tabla 1}

Reformas en el sistema financiero español (noviembre de 2008-mayo de 2012)

\begin{tabular}{|c|c|}
\hline Plan E (noviembre 2008) & $\begin{array}{l}\text { - Creación del Fondo de Adquisición de Activos Financieros. } \\
\text { - Aumento de los importes máximos garantizados por los FGD: } 100.000 € \text { por } \\
\text { depositante. } \\
\text { - Avales del Estado para las nuevas emisiones de deuda de las entidades de } \\
\text { crédito. } \\
\text { - Adquisición estatal de títulos para reforzar los recursos propios de las } \\
\text { entidades (no se llegó a emplear). }\end{array}$ \\
\hline $\begin{array}{l}\text { Real Decreto-Ley } 9 / 2009 \text {, } \\
\text { de } 26 \text { de junio }\end{array}$ & $\begin{array}{l}\text { - Reestructuración ordenada del sistema bancario. Objetivo: mantener la } \\
\text { confianza en el sistema financiero nacional e incrementar su fortaleza y sol- } \\
\text { vencia. } \\
\text { - El modelo propuesto se articuló en torno a: } \\
\text { > Los tres FGD. } \\
\text { Dna nueva institución: el FROB. Funciones: la gestión de los procesos } \\
\text { de reestructuración y el reforzamiento de los recursos propios en deter- } \\
\text { minados procesos de integración. }\end{array}$ \\
\hline $\begin{array}{l}\text { Real Decreto-Ley 11/2010, } \\
\text { de } 9 \text { de julio }\end{array}$ & $\begin{array}{l}\text { - Reforma del régimen jurídico de las cajas de ahorros: mayor profesionaliza- } \\
\text { ción de sus órganos de gobierno. } \\
\text { - Refuerzo de su capacidad para obtener recursos propios de máxima } \\
\text { calidad, con el objetivo de favorecer su posición competitiva y su credibili- } \\
\text { dad en los mercados. }\end{array}$ \\
\hline
\end{tabular}

${ }^{11}$ Reforzado además por el Real Decreto-Ley 18/2012, de 11 de mayo, sobre saneamiento y venta de los activos inmobiliarios del sector financiero, que incluyó tres importantes disposiciones: reforzamiento de las exigencias de provisiones a las entidades de crédito para los activos vinculados con el sector inmobiliario; nueva modificación de la normativa del FROB, para que aquellas entidades con capital principal o recursos propios deficitarios para cumplir estos requerimientos de provisiones adicionales pudieran solicitar apoyo financiero público a través de su intervención, que podría consistir en inyectar recursos mediante la adquisición bien de capital ordinario, o bien de otros instrumentos convertibles en capital; y la previsión de la constitución de Sociedades para la Gestión de Activos (lo que en otros ámbitos se han denominado "bancos malos"), con el fin de que las entidades de crédito intervenidas o recapitalizadas por el FROB les cedan sus activos inmobiliarios para descongestionar sus balances y permitir que, cuanto antes, fluya el crédito hacia el sector privado no financiero de la economía. 
Tabla 1 (continuación)

Reformas en el sistema financiero español (noviembre de 2008-mayo de 2012)

\begin{tabular}{|c|c|}
\hline $\begin{array}{l}\text { Real Decreto-Ley 2/2011, } \\
\text { de } 18 \text { de febrero }\end{array}$ & $\begin{array}{l}\text { - Refuerzo del nivel de solvencia de todas las entidades de crédito, con la } \\
\text { finalidad de salvaguardar la estabilidad y eficiencia del sistema financiero. } \\
\text { - Fase final de los procesos de reestructuración de entidades. }\end{array}$ \\
\hline $\begin{array}{l}\text { Real Decreto-Ley 2/2012, } \\
\text { de } 3 \text { de febrero }\end{array}$ & $\begin{array}{l}\text { - Saneamiento de los balances de las entidades de crédito de activos } \\
\text { relacionados con el sector inmobiliario, para que puedan canalizar el ahorro } \\
\text { hacia proyectos de inversión eficientes. } \\
\text { - Eliminación de los excesos de capacidad instalada. } \\
\text { - Fortalecimiento de la gobernanza de las entidades resultantes de los proce- } \\
\text { sos de integración, especialmente de las cajas de ahorros. } \\
\text { - Garantizar que los costes del saneamiento del sistema financiero no recai- } \\
\text { gan sobre el sector público. }\end{array}$ \\
\hline $\begin{array}{l}\text { Real Decreto-Ley } 18 / 2012 \text {, } \\
\text { de } 11 \text { de mayo }\end{array}$ & $\begin{array}{l}\text { - Nuevo refuerzo de las exigencias de provisiones para los activos vinculados } \\
\text { al sector inmobiliario. } \\
\text { - Nueva modificación de la normativa del FROB. } \\
\text { - Previsión de la creación de Sociedades para la Gestión de Activos ("bancos } \\
\text { malos"). }\end{array}$ \\
\hline
\end{tabular}

Fuente: Elaboración propia.

\subsection{El rescate bancario en España (junio de 2012-enero de 2014)}

Durante el primer trimestre de 2012, las tensiones en los mercados de deuda soberana europea fueron en aumento, pues la rentabilidad exigida a la deuda pública española era cada vez mayor, lo que se tradujo en un considerable incremento de su prima de riesgo que dificultó la capacidad de ajuste presupuestario y la recuperación económica. Ante esta situación, y con el objeto de reforzar la confianza sobre la solvencia de la banca española y determinar el nivel de capital que asegurara su viabilidad a largo plazo, el Consejo de Ministros de nuestro país, en su Resolución de 11 de mayo, encomendó al Ministerio de Economía y Competitividad que encargara un análisis externo de carácter agregado (top-down) para evaluar la resistencia del sector bancario español ante un severo deterioro adicional de la economía.

Así, el Banco de España, en coordinación con el Ministerio de Economía y Competitividad, acordó la contratación de Roland Berger y Oliver Wyman como consultores independientes, es decir, para realizar una estimación de las necesidades de capital de nuestro sector bancario para hacer frente al impacto de situaciones adversas en las carteras crediticias de las entidades.

El 21 de junio de 2012 se publicaron los resultados de estas pruebas de resistencia $^{12}$, efectuadas a 14 grupos bancarios ${ }^{13}$ (que representaban en torno al

${ }^{12}$ Véase, para una información más detallada, ROLAND BERGER (2012) y OLIVER WYMAN (2012a).

${ }^{13}$ Santander; BBVA\&Unnim; Popular\&Pastor; Sabadell\&CAM; Bankinter; Caixabank\&Banca Cívica; Bankia-BFA; KutxaBank; Ibercaja\&Caja3\&Liberbank; Unicaja\&CEISS; Banco Mare Nostrum; Catalunya Bank; NCG Banco y Banco de Valencia. 
90\% de nuestro sistema financiero) ante dos escenarios macroeconómicos distintos, confirmándose, en general, las conclusiones del Programa de Evaluación del Sector Financiero (FSAP) ${ }^{14}$, llevado a cabo por el Departamento de Mercados Monetarios y de Capitales del Fondo Monetario Internacional durante los meses de febrero y abril de 2012, que señaló que los problemas se concentraban, fundamentalmente, en las entidades participadas por el FROB o que ya habían solicitado importantes ayudas públicas. En concreto, en el escenario macroeconómico base, con un core Tier 1 del 9\%, las necesidades de capital de nuestro sector bancario se situarían entre 16.000 y 26.000 millones de euros, mientras que en el escenario macroeconómico adverso, con un core Tier 1 del $6 \%$, estas necesidades estarían en un rango de entre 51.000 y 62.000 millones de euros.

Una vez conocidos los resultados de este primer análisis de carácter agregado, el 25 de junio de 2012 el Gobierno español solicitó formalmente asistencia financiera externa en el contexto del proceso en curso de reestructuración y recapitalización de su sector bancario. Finalmente, el rescate de la banca española fue aprobado por los países del Eurogrupo en la Cumbre celebrada en Bruselas el 29 de junio de 2012, especificándose, asimismo, que sería el Mecanismo Europeo de Estabilidad (MEDE) ${ }^{15}$ el responsable de prestar esta asistencia, una vez que la institución estuviese plenamente operativa.

Posteriormente, se iniciaron las negociaciones con los socios europeos para la aprobación de un Memorándum de Entendimiento, ratificado por el Consejo Europeo el 20 de julio de 2012, en el que se recogían las medidas a adoptar para reforzar aún más la estabilidad del sistema financiero, de acuerdo con una hoja de ruta o calendario establecido. Así, los principales objetivos del programa ${ }^{16}$ eran: el aumento de la flexibilidad a largo plazo del conjunto del sector bancario español, mediante una mayor transparencia de los balances bancarios para facilitar una menor exposición al sector inmobiliario; el restablecimiento de la financiación basada en el mercado; la reducción de la dependencia de las entidades del apoyo del Banco Central para asegurar su liquidez; y, por último, el perfeccionamiento de los mecanismos para controlar riegos y evitar futuras crisis financieras.

\footnotetext{
${ }^{14}$ INTERNATIONAL MONETARY FUND (2012).

${ }^{15}$ El MEDE es un organismo intergubernamental creado por el Consejo Europeo en marzo de 2011, que funciona, desde su entrada en vigor en julio de 2012, sustituyendo las estructuras temporales del Fondo Europeo de Estabilidad Financiera (FEEF) y del Mecanismo Europeo de Estabilidad Financiera (MEEF), como un mecanismo permanente para la salvaguardia de la estabilidad financiera en la Eurozona, puesto que, bajo unas condiciones estrictas, facilitará ayuda financiera en forma de préstamos a los países que sufran graves problemas de financiación.

${ }^{16}$ Véase: MINISTERIO DE ASUNTOS EXTERIORES Y DE COOPERACIÓN (2012).
} 
Por otro lado, un componente clave del programa de asistencia financiera reflejado en el Memorando fue la revisión de las debilidades o segmentos vulnerables del sector bancario español, que consta de los tres elementos siguientes ${ }^{17}$ :

- Identificación de las necesidades de capital de cada entidad bancaria, a través de un análisis general de la calidad de sus activos y una prueba de resistencia banco por banco (análisis bottom-up) ante un hipotético escenario macroeconómico muy adverso.

- Recapitalización, reestructuración y/o resolución de las entidades más vulnerables, sobre la base de planes que aborden los déficits de capital detectados en la prueba de resistencia.

- Segregación de los activos dañados de los bancos que necesiten apoyo público para su recapitalización y, finalmente, transferencia de los mismos a una sociedad externa de gestión de activos ("banco malo").

Así pues, en primer lugar, según lo previsto en la hoja de ruta del Memorando de Entendimiento, y como extensión natural de las pruebas de resistencia top-down, se procedió a realizar el análisis bottom-up, encargado a Oliver Wyman, con la participación de expertos independientes (consultores, auditores y valoradores inmobiliarios, nacionales e internacionales), del Banco de España y del Ministerio de Economía y Competitividad, y con la supervisión de la Comisión Europea, del Banco Central Europeo, de la Autoridad Bancaria Europea y del Fondo Monetario Internacional.

En este test de estrés se efectuó un examen más amplio y detallado de la resistencia del sector, pues incluyó una valoración exhaustiva y pormenorizada de las carteras de crédito al sector privado residente y de los activos inmobiliarios, así como de la capacidad para absorber pérdidas en los próximos tres años en un entorno muy adverso, de las entidades integrantes de los 14 grupos bancarios objeto del análisis (los mismos que para las pruebas top-down).

Los resultados ${ }^{18}$, publicados el 28 de septiembre de 2012, confirmaron que el sistema bancario español era mayoritariamente solvente y viable, incluso en un escenario macroeconómico extremadamente adverso y altamente improbable $^{19}$, pues siete grupos bancarios, que representaban más del $62 \%$ de la cartera crediticia analizada, no precisaban capital adicional, identificándose, por otro lado, para el resto de grupos, unas necesidades adicionales de 53.745 millones de euros, siempre y cuando se tuvieran en cuenta los procesos de integración en marcha por aquellos momentos y los efectos fiscales.

\footnotetext{
${ }^{17}$ Para una mayor información, puede consultarse BANCO DE ESPAÑA (2012).

${ }^{18}$ OLIVER WYMAN (2012b).

${ }^{19}$ Se tomaron como referencia los mismos escenarios macroeconómicos que para las pruebas de resistencia top-down.
} 
Partiendo de los resultados obtenidos en la prueba de resistencia bottom-up y de la valoración de los planes de reestructuración, se procedió a efectuar una clasificación de las entidades bancarias españolas en cuatro grandes grupos:

- El grupo 0, formado por los bancos que no necesitaron ayuda externa ni que requirieron de otras actuaciones adicionales. Como estaba previsto, los dos principales grupos financieros de nuestro país, Santander y BBVA, así como Caixabank y Banca Cívica, Kutxabank, Sabadell y CAM y Bankinter, no precisaron incrementar su capital, ni siquiera para enfrentarse al escenario macroeconómico adverso planteado por la consultora. A este grupo 0 se sumó también Banco Popular.

- El grupo 1, ya predefinido e integrado por las entidades que habían sido nacionalizadas por el FROB con anterioridad a la solicitud del rescate bancario, es decir, Bankia-BFA, Catalunya Banc, NCG Banco y Banco de Valencia.

- El grupo 2, del que formaron parte los bancos con déficit de capital, según el test de estrés, y que no pudieron afrontar dicho déficit de forma privada y sin ayuda estatal: Caja 3, Banco Mare Nostrum, Banco Ceiss y Liberbank.

- El grupo 3, que finalmente quedó vacío, ya que ninguna entidad con necesidades de capital pudo presentar un plan fiable de recapitalización sin recurrir a la ayuda del Estado.

Posteriormente, con el fin de garantizar la estabilidad del sistema financiero y la disciplina del mercado, asegurar una utilización eficiente de los recursos públicos y proteger a los clientes de las entidades de crédito, el Gobierno español aprobó la Ley 9/2012, de 14 de noviembre, de reestructuración y resolución de entidades de crédito, cumpliendo, de esta manera, con el segundo paso establecido en el programa de asistencia financiera incluido en el Memorando de Entendimiento ${ }^{20}$.

Esta Ley, además de establecer el régimen jurídico del FROB y su marco general de actuación, así como un nuevo procedimiento de comercialización de instrumentos híbridos de capital y de productos financieros complejos para inversores minoristas, tiene como principal objeto regular los procesos de actuación temprana, aplicable a las entidades en caso de incumplimiento real o

${ }^{20}$ Hasta finales del año 2012, las autoridades españolas también aprobaron la Ley 8/2012, sobre saneamiento y venta de los activos inmobiliarios del sector financiero, en la que, entre otras medidas, se flexibilizan los requerimientos de provisiones establecidos por el Real Decreto-Ley $2 / 2012$, para las entidades que vayan a acometer procesos de integración, pues se las deja un plazo de 12 meses desde la autorización de ese proceso para su cumplimiento, se regula la creación de las Sociedades para la Gestión de Activos y se modifica la Ley de Autonomía del Banco de España en relación de las competencias que corresponden a sus órganos de gobierno. 
potencial de requerimientos de solvencia, liquidez, estructura organizativa o control interno, siempre que se encuentren en disposición de retornar al cumplimiento por sus propios medios; reestructuración, en el caso de que la entidad requiera apoyo financiero público para garantizar su viabilidad y existan elementos objetivos que hagan razonablemente previsible que dicho apoyo será reembolsado o recuperado; y resolución, cuando la entidad sea inviable y, por razones de interés público y estabilidad financiera, resulte necesario evitar su liquidación concursal.

Por otro lado, dentro del conjunto de instrumentos de reestructuración y resolución de entidades de crédito diseñados por la Ley 9/2012, se establece la creación de las llamadas sociedades de gestión de activos, cuyo cometido es permitir la concentración de aquellos activos considerados como problemáticos o que pueden dañar el balance de las entidades, facilitando, de este modo, su gestión y logrando que, desde su transmisión, se produzca una traslación efectiva de los riesgos vinculados a estos activos.

Así, para cumplir con este precepto y con uno de los principales hitos del Memorando de Entendimiento, el Gobierno aprobó el Real Decreto 1559/2012, de 15 de noviembre, en el que se reguló el régimen de organización y funcionamiento de la Sociedad de Gestión de Activos Procedentes de la Reestructuración Bancaria (Sareb), constituida como sociedad anónima (al 45\% con fondos públicos y al 55\% con capital privado) el 28 de noviembre de 2012 para liquidar, en un plazo máximo de 15 años, los activos financieros e inmobiliarios procedentes de los bancos españoles que habían recibido ayudas públicas (Bankia, Catalunya Banc, NCG Banco, Banco de Valencia, Caja 3, Banco Mare Nostrum, Banco Ceiss y Liberbank), tratando de obtener el máximo valor por ellos, y permitiendo, de esta forma, la devolución de su deuda, avalada por el Estado español.

Además, el Memorando de Entendimiento exigió a las autoridades españolas la adopción de una serie de medidas adicionales para reforzar el marco regulador y de supervisión de nuestro sector bancario, con el objetivo último de mejorar su fortaleza y resistencia a nivel internacional. Entre estas medidas destacan las siguientes ${ }^{21}$ :

- Las entidades de crédito deberán cumplir, desde el 31 de diciembre de 2012 y al menos hasta finales de 2014, un coeficiente de solvencia del 9\% como mínimo.

- Desde el 1 de enero de 2013, las entidades no podrán reducir su capital social respecto a las cifras contabilizadas en sus balances en diciembre de 2012, sin la previa autorización del Banco de España.

${ }^{21}$ Para una información más detallada, véase MINISTERIO DE ASUNTOS EXTERIORES Y DE COOPERACIÓN (2012, pp. 12-15). 
- El Banco de España vigilará de cerca la situación de liquidez de las entidades receptoras de ayuda pública (grupos 1 y 2) e informará periódicamente a la Comisión Europea, al Banco Central Europeo y al Fondo Monetario Internacional.

- Una nueva reforma de los mecanismos de gobernanza de las antiguas cajas de ahorros y de los bancos comerciales bajo control estatal.

- Una mejora de la trasparencia y confianza del sistema bancario español a través de un incremento de la cantidad y calidad de la información facilitada por las entidades de crédito a la ciudadanía.

- La transferencia de las competencias sancionadoras desde el Ministerio de Economía al Banco de España, con el objetivo de reforzar su independencia operativa.

- Una revisión interna de los procedimientos de supervisión y decisión del Banco de España, a fin de detectar deficiencias e introducir las mejoras necesarias.

- Las entidades de crédito deberán revisar la calidad de sus activos y, si procede, preparar y aplicar estrategias para hacer frente al deterioro de los mismos.

Finalmente, tras el compromiso del Gobierno español de corregir la situación de déficit público excesivo antes de $2014^{22}$ e implementar las reformas estructurales necesarias ${ }^{23}$ para corregir los desequilibrios macroeconómicos, el 12 de diciembre de 2012 fue transferido el primer tramo del rescate bancario, que ascendió a 39.468 millones de euros, por el MEDE al FROB. El segundo tramo de 1.865 millones de euros del rescate bancario concedido por el Eurogrupo, fue desembolsado el 5 de febrero de 2013 en forma de bonos del MEDE al FROB, que a su vez hizo llegar a las entidades beneficiarias del grupo 2. A cambio de la ayuda, las entidades se comprometieron a reducir su tamaño de media un $30 \%$ y a reorientar su modelo empresarial para centrarlo en el negocio minorista y en la concesión de préstamos a las PYMES en las regiones en las que habían

${ }^{22}$ Se exigió alcanzar un déficit del 6,3\% del PIB en 2012, del 4,5\% del PIB en 2013 y del 2,8\% del PIB en 2014.

${ }^{23}$ En concreto, se recomendó a España la introducción de un sistema tributario acorde con los esfuerzos de consolidación fiscal y más propicio para el crecimiento; la disminución del sesgo inducido por la fiscalidad a favor del endeudamiento y la propiedad de vivienda; la aprobación de una reforma del mercado de trabajo; la adopción de medidas complementarias para aumentar la eficacia de las políticas activas del mercado de trabajo; la aplicación de políticas que favorezcan la apertura de los servicios profesionales, reduzcan las demoras para obtener licencias y permisos para abrir nuevos negocios y eliminen los obstáculos a la actividad empresarial; y, por último, la interconexión de las redes eléctricas y de gas con los países vecinos y la resolución del problema de déficit tarifario en la electricidad. 
operado tradicionalmente, limitando, además, su presencia en el sector de la banca mayorista y en el de promoción inmobiliaria.

Una vez finalizado el Programa de Asistencia Financiera a España, cuyos acontecimientos más destacables han quedado resumidos en la Tabla 2, podemos observar, a continuación, en la Tabla 3, el profundo cambio que se ha producido, desde el inicio de la crisis financiera internacional a mediados de 2007, en la estructura del sistema bancario español, pues desde 2008 se ha registrado el cese de actividades de 38 entidades de crédito. Gran parte de este cambio se ha concentrado en la transformación de las cajas de ahorros y su manifestación más visible ha sido el intenso proceso de consolidación y redimensionamiento por ellas vivido.

Tabla 2

El rescate bancario de España

(cronología)

\begin{tabular}{|c|c|}
\hline 21 de junio de 2012 & $\begin{array}{l}\text { Resultados de las pruebas de resistencia agregadas (top-down): las } \\
\text { necesidades de capital se concentraban en las entidades participadas por el } \\
\text { FROB o que ya habian precisado importantes ayudas públicas. }\end{array}$ \\
\hline 25 de junio de 2012 & El Gobierno español solicitó formalmente asistencia financiera externa. \\
\hline 29 de junio de 2012 & $\begin{array}{l}\text { El Eurogrupo aprobó el rescate de la banca española en la Cumbre celebrada } \\
\text { en Bruselas. }\end{array}$ \\
\hline 20 de julio de 2012 & $\begin{array}{l}\text { El Consejo Europeo ratificó el "Memorando de Entendimiento sobre condiciones } \\
\text { de política sectorial financiera", en el que se recogen las medidas que deberán } \\
\text { adoptarse para reforzar aún más la estabilidad del sistema financiero español, } \\
\text { de acuerdo con una hoja de ruta o calendario establecido. }\end{array}$ \\
\hline 28 de septiembre de 2012 & $\begin{array}{l}\text { - Resultados de las pruebas de resistencia bottom-up (necesidades de capital } \\
\text { de cada entidad): el sistema bancario español era mayoritariamente solvente } \\
\text { y viable, incluso en un escenario macroeconómico extremadamente adverso. } \\
\text { - Se clasificaron las entidades en cuatro grandes grupos: } \\
>\text { Grupo 0: bancos que no necesitaron ayuda externa. } \\
>\text { Grupo 1: entidades que habian sido nacionalizadas por el FROB (Bankia, } \\
\text { Catalunya Banc, NCG Banco y Banco de Valencia). } \\
\text { Grupo 2: bancos con déficit de capital y que no pudieron afrontarlo de } \\
\text { forma privada (Caja 3, Banco Mare Nostrum, Banco Ceiss y Liberbank). } \\
\text { Grupo 3: quedó vació, pues ninguna entidad con necesidades de capital } \\
\text { pudo presentar un plan fiable de recapitalización sin recurrir a la ayuda } \\
\text { estatal. }\end{array}$ \\
\hline 15-26 de octubre de 2012 & $\begin{array}{l}1^{a} \text { revisión del Programa de Asistencia Financiera por parte de la CE, el BCE y } \\
\text { el FMl: } \\
\text { - Análisis de la situación macrofinanciera y del rendimiento de las } \\
\text { entidades. } \\
\text { - Análisis de la situación y del avance de las condiciones horizontales } \\
\text { exigidas en el Memorando. } \\
\text { - Acuerdos con el Gobierno español para el diseño y funcionamiento de la } \\
\text { futura sociedad de gestión de activos. }\end{array}$ \\
\hline 14 de noviembre de 2012 & $\begin{array}{l}\text { Ley } 9 / 2012 \text {, de reestructuración y resolución de entidades de crédito, con el fin } \\
\text { de garantizar la estabilidad del sistema financiero y la disciplina del mercado, } \\
\text { asegurar una utilización eficiente de los recursos públicos y proteger a los } \\
\text { clientes de las entidades bancarias. }\end{array}$ \\
\hline 15 de noviembre de 2012 & $\begin{array}{l}\text { Real Decreto 1559/2012, en el que se reguló el régimen de organización y } \\
\text { funcionamiento de la Sociedad de Gestión de Activos Procedentes de la } \\
\text { Reestructuración Bancaria (Sareb). }\end{array}$ \\
\hline
\end{tabular}




\section{Tabla 2 (continuación) \\ El rescate bancario de España \\ (cronología)}

\begin{tabular}{|c|c|}
\hline 28 de noviembre de 2012 & $\begin{array}{l}\text { Constitución de la Sareb, con el objetivo de liquidar, en un plazo máximo de } 15 \\
\text { años, los activos financieros e inmobiliarios procedentes de los bancos } \\
\text { beneficiarios de las ayudas públicas. }\end{array}$ \\
\hline 12 de diciembre de 2012 & $\begin{array}{l}\text { El } 1^{\text {er }} \text { tramo del rescate bancario, destinado a los bancos nacionalizados y a la } \\
\text { Sareb ( } 39.468 \text { millones de } € \text { ), fue transferido por el MEDE al FROB. }\end{array}$ \\
\hline $\begin{array}{l}28 \text { de enero }-1 \text { de febrero de } \\
2013\end{array}$ & $\begin{array}{l}2^{a} \text { Revisión del Programa de Asistencia Financiera: } \\
\text { - Progreso de la aplicación del programa gracias a la mejora de las } \\
\text { condiciones en los mercados financieros. } \\
\text { - Mayor estabilidad en el sector bancario por la aprobación de planes de } \\
\text { reestructuración, la recapitalización de las entidades que han recibido ayudas } \\
\text { públicas, la creación de la Sareb y la suavización de las restricciones de } \\
\text { financiación. } \\
\text { - Importantes progresos en las condiciones horizontales del Memorando. } \\
\text { - Siguen siendo necesarios nuevos avances en el saneamiento de las finanzas } \\
\text { públicas, en el fortalecimiento del marco institucional y en la aplicación del } \\
\text { programa de reformas estructurales. }\end{array}$ \\
\hline 5 de febrero de 2013 & $\begin{array}{l}\text { Desembolso del } 2^{\circ} \text { tramo de } 1.865 \text { millones de } € \text { del rescate bancario, } \\
\text { destinado a las entidades del grupo } 2 \text {. }\end{array}$ \\
\hline 21 - 31 de mayo de 2013 & $\begin{array}{l}3^{a} \text { revisión del Programa de Asistencia Financiera: } \\
\text { - Mayor estabilidad de los mercados financieros, mejora de la situación de } \\
\text { liquidez y refuerzo de la posición de solvencia del sector bancario. } \\
\text { - Importantes progresos en el proceso de reestructuración del sector bancario, } \\
\text { en la separación de los activos deteriorados y en la aplicación de las } \\
\text { condiciones horizontales. } \\
\text { - Se debe continuar avanzando en la consolidación gradual de las finanzas } \\
\text { públicas, en el refuerzo de las administraciones públicas y en la } \\
\text { implementación de las reformas de los mercados de productos y factores. }\end{array}$ \\
\hline 16 - 27 de septiembre de 2013 & $\begin{array}{l}\text { 4a revisión del Programa de Asistencia Financiera: } \\
\text { - Descenso de los rendimientos de la deuda soberana y mejora de las } \\
\text { condiciones de financiación. } \\
\text { - Mejora de la situación de liquidez y de la estructura de financiación del sector } \\
\text { bancario, debido al aumento de los depósitos bancarios y a la recuperación } \\
\text { del acceso a los mercados financieros. } \\
\text { - Cómoda situación de solvencia de las entidades tras la recapitalización de } \\
\text { parte del sector y la transferencia de activos a la Sareb. } \\
\text { - Refuerzo del marco de gobernanza, regulación y supervisión del sector } \\
\text { bancario, gracias al cumplimiento casi total de las condiciones horizontales. } \\
\text { - Sigue siendo necesaria la recuperación de la confianza en la economía } \\
\text { española mediante reformas encaminadas a estabilizar el sistema de } \\
\text { pensiones, unificar el mercado interno, liberalizar los servicios profesionales, } \\
\text { mejorar la eficacia de la Administración local y aumentar el dinamismo de los } \\
\text { mercados de productos y servicios. }\end{array}$ \\
\hline 2 - 13 de diciembre de 2013 & $\begin{array}{l}\text { Quinta y última revisión del Programa de Asistencia Financiera: } \\
\text { - España ha superado graves problemas en algunos ámbitos de su sector } \\
\text { bancario gracias a las reformas y medidas adoptadas, con el apoyo de la } \\
\text { Eurozona y de iniciativas europeas más amplias. } \\
\text { - Cumplimiento completo de la condicionalidad horizontal prevista en el } \\
\text { Memorando de Entendimiento. } \\
\text { - El respeto pleno de los objetivos de saneamiento presupuestario acordados, } \\
\text { con el fin de revertir el aumento de la deuda pública, y la conclusión del } \\
\text { programa de reformas siguen siendo imperativos para que la economía } \\
\text { vuelva a una senda de crecimiento sostenible. }\end{array}$ \\
\hline 23 de enero de 2014 & $\begin{array}{l}\text { Finalización del Programa de Asistencia Financiera: La CE, en coordinación con } \\
\text { el BCE y el FMI, continuará realizando un seguimiento del sector financiero y } \\
\text { del conjunto de la economía española en el marco de los procesos de vigilancia } \\
\text { de la UE. }\end{array}$ \\
\hline
\end{tabular}

Fuente: Comisión y elaboración propia. 
Fruto de la situación en la que se encuentra el sector de cajas de ahorros en España durante la crisis, nuestras autoridades han aprobado una nueva normativa reguladora para estas entidades, la Ley 26/2013, de 27 de diciembre, de cajas de ahorros y fundaciones bancarias, que contempla una profunda reforma de su régimen jurídico, pues pretende conjugar los valores tradicionales de estas entidades, es decir, su carácter social y fuerte arraigo territorial, con la necesidad de garantizar su estabilidad financiera y, por tanto, del conjunto de nuestro sistema bancario $^{24}$. Para lograr este objetivo, se incluyen tres importantes disposiciones:

- La delimitación de la actividad de las cajas de ahorros, que se orientará exclusivamente a la captación de depósitos y a la concesión de préstamos en un ámbito de actuación restringido a una Comunidad Autónoma o a provincias limítrofes (un máximo de 10). De esta forma, se pretende evitar que las cajas tengan un tamaño excesivo que pudiera generar un posible riesgo sistémico en el conjunto del sistema financiero, $\mathrm{y}$, además, vincular su función social a un área geográfica con unas características, peculiaridades y necesidades comunes.

- El endurecimiento del régimen de incompatibilidades, ya que no podrán ser miembros de los órganos de gobierno de las cajas los cargos ejecutivos de partidos políticos, sindicatos y asociaciones profesionales, así como los cargos electos y altos cargos de Administraciones Públicas, o que lo hayan sido en los dos años anteriores.

- La posible transformación de cajas de ahorros en fundaciones bancarias ${ }^{25}$, dirigidas a la atención y desarrollo de su obra social y a la gestión de su participación en la entidad, en cuyo caso, la caja tendrá que traspasar su actividad financiera a una entidad de crédito si el valor de su activo excede de 10.000 millones de euros o su cuota de mercado en depósitos en su Comunidad Autónoma supera el 35\%.

Sin embargo, ni el ámbito de la reorganización del sistema financiero español se ha limitado a las cajas de ahorros, ni su único hito ha sido la reducción en el número de partícipes en el mercado, sino que la reforma del sistema ha abordado aspectos muy diversos de la organización del negocio, y ha abarcado a todas las entidades de nuestro sector bancario.

Como podemos comprobar en la Tabla 3, además de la reducción del número de cajas de ahorros, se ha producido también un importante ajuste en el

\footnotetext{
${ }^{24}$ Un excelente estudio sobre las razones de la crisis de las cajas de ahorros en nuestro país, puede verse en Climent (2012).

${ }^{25}$ La Ley las define como aquellas que mantengan una participación en una entidad de crédito que alcance, de forma directa o indirecta, al menos un $10 \%$ del capital o los derechos de voto, o bien que le permita nombrar o destituir algún miembro de su órgano de administración.
} 
sector de las cooperativas de crédito, pues de las 93 existentes en 2000, su número pasó a finales de 2012 a 68. Este proceso de reducción, más intenso durante la crisis, ha respondido a una estrategia de estas entidades que se puede dividir en dos fases: en la primera, caracterizada por el desarrollo de una actividad de banca universal, con mayor presencia de algunas en otros territorios distintos de los tradicionales, y de reestructuración y racionalización de sus procesos de gestión (Palomo y Sanchís, 2008); y una segunda, caracterizada por un ajuste del número de entidades a través de la realización de fusiones, o la creación de grupos de ellas (Unión Nacional de Cooperativas de Crédito, 2013).

Tabla 3

El proceso de reestructuración de las entidades de depósito españolas (2000-2012) (número de entidades)

\begin{tabular}{|l|r|r|r|r|r|r|r|r|r|r|r|r|r|}
\hline & $\mathbf{2 0 0 0}$ & $\mathbf{2 0 0 1}$ & $\mathbf{2 0 0 2}$ & $\mathbf{2 0 0 3}$ & $\mathbf{2 0 0 4}$ & $\mathbf{2 0 0 5}$ & $\mathbf{2 0 0 6}$ & $\mathbf{2 0 0 7}$ & $\mathbf{2 0 0 8}$ & $\mathbf{2 0 0 9}$ & $\mathbf{2 0 1 0}$ & $\mathbf{2 0 1 1}$ & $\mathbf{2 0 1 2}$ \\
\hline Bancos & 143 & 146 & 144 & 139 & 137 & 140 & 144 & 151 & 156 & 154 & 161 & 165 & 160 \\
\hline Cajas de Ahorros & 48 & 47 & 47 & 47 & 47 & 47 & 47 & 46 & 46 & 46 & 36 & 35 & 17 \\
\hline C. Crédito & 93 & 89 & 85 & 84 & 83 & 83 & 83 & 82 & 81 & 80 & 78 & 74 & 68 \\
\hline Total & $\mathbf{2 8 4}$ & $\mathbf{2 8 2}$ & $\mathbf{2 8 0}$ & $\mathbf{2 7 0}$ & $\mathbf{2 6 7}$ & $\mathbf{2 7 0}$ & $\mathbf{2 7 4}$ & $\mathbf{2 7 9}$ & $\mathbf{2 8 3}$ & $\mathbf{2 8 0}$ & $\mathbf{2 7 5}$ & $\mathbf{2 7 4}$ & $\mathbf{2 4 5}$ \\
\hline
\end{tabular}

Fuente: Elaboración propia a partir de los datos suministrados por Banco de España.

\section{EL IMPACTO COMPARADO DE LA CRISIS SOBRE LA ACTIVIDAD BANCARIA}

Así pues, los cambios sufridos por el sistema bancario español a lo largo de los últimos años han sido muy intensos, lo que ha propiciado un ajuste significativo en el número de entidades, de oficinas y de empleados, que contrasta con la tendencia que había mantenido en los períodos anteriores de una gran proximidad a la clientela, con un servicio dirigido muy especialmente por las entidades más representativas a los clientes particulares.

Estos cambios regulatorios se han llevado a cabo con el fin de fortalecer a nuestras entidades y conseguir una mayor confianza y credibilidad sobre su futuro en los mercados financieros, fundamentalmente los internacionales, pero es cierto igualmente que la estrategia seguida ha cambiado algunos de los indicadores básicos del sector, tanto en lo referente a su presencia y tamaño, al servicio ofrecido y a la operativa desarrollada.

Estos cambios en el sistema financiero español, y en el del conjunto de los países de la UE, están no obstante lejos de conocer su dimensión definitiva. Al margen de las modificaciones en sus cifras más significativas, comparadas con las de otros países que han recibido ayudas públicas para el saneamiento de sus sistemas financieros, que analizaremos a continuación, se están empezando a adoptar cambios en la legislación financiera de cada Estado miembro de la UE con el fin de avanzar en el proceso hacia una Unión Bancaria. 
Este proceso consta, como es sabido, de tres pilares (un Mecanismo Único de Supervisión, un Fondo de Resolución-Reestructuración europeo y un Fondo de Garantía de Depósitos europeo), y su desarrollo va a provocar una transformación en la configuración de los sistemas financieros europeos, desde un contexto más nacional a otro en el que el proceso de integración financiera va a conseguir un impulso casi definitivo ${ }^{26}$.

Con el fin de conocer el impacto conjunto de los cambios regulatorios y de las propias estrategias de las entidades bancarias, en las Tablas 4, 5 y 6 se incluyen respectivamente la evolución de los datos relativos a la presencia y al tamaño bancario, la de los indicadores de servicio y de operativa bancaria, pero se ofrecen en comparación con los correspondientes a los de otros países cuyos sistemas bancarios han precisado ayudas públicas para su saneamiento, para así conocer no sólo las modificaciones que se han producido en estas ratios en nuestro país, sino también si esa misma tendencia se viene observando en sistemas bancarios en crisis.

Una visión global de todos estos datos referida al sistema bancario español, nos permite constatar algunas de las afirmaciones anteriormente realizadas. En concreto, desde prácticamente principios de este siglo, podemos destacar que el número de entidades bancarias en nuestro país se ha reducido en un 13,6\%, siendo esa disminución continua desde el inicio de la crisis (frente a su reducción hasta 2004 y el aumento hasta 2008), pues la cifra de 2008 y de 2002 es la misma; esta crisis ha visto disminuir significativamente la tasa de crecimiento de los activos bancarios tanto respecto a cada entidad (hasta el $14,5 \%$ en la crisis, frente al aumento del $133,8 \%$ en el intervalo entre 2002 y 2008), al PIB español $(0,26 \%$ de incremento en crisis frente al $56,8 \%$ en el período previo) y por habitante (con una caída del 1,5\% en crisis frente al incremento del 112,5\% antes de la misma); y como resultado se ha producido un aumento del grado de concentración bancaria en España de 9 puntos porcentuales, desde un 42,4\% en 2008 hasta un $51,4 \%$ en 2012.

La reducción del número de oficinas se constata igualmente, con una caída de más de 3 mil en el intervalo de los últimos cinco años, lo que contrasta con el aumento en más de 2 mil del período anterior. En cambio el ajuste en el número de empleados ha sido prácticamente continuo en el período contemplado, lo que

${ }^{26}$ El desarrollo de estos tres pilares no resulta sencillo por las reticencias de algunos países en los procesos de negociación que se están llevando a cabo. El Mecanismo Único de Supervisión es el que ha conocido unos mayores avances al acordarse de que sea el Banco Central Europeo el que lleve cabo esas tareas supervisoras para las entidades que tengan un volumen de activos superiores a los 30 mil millones de euros (o tenga un tamaño superior al 20\% del PIB del país). Este acuerdo se ha plasmado en el Reglamento de la UE 1024/2013, de 15 de octubre, que encomienda al BCE tareas específicas respecto a las políticas relacionadas con la supervisión prudencial de las entidades de crédito. 
supone un descenso en casi 10 mil trabajadores. Todo ello ha hecho que las ratios de empleados por oficina y por habitante y el de oficinas por habitante se hayan reducido.

Esa evolución del número de entidades, de oficinas y de empleados en el sector bancario de nuestro país ha condicionado las ratios de los depósitos y préstamos respecto al PIB, a los habitantes y al número de oficinas. En efecto, respecto a los depósitos, y en relación al PIB, se produce un movimiento creciente hasta 2009 , merced al fuerte crecimiento de la actividad bancaria, para reducirse a partir de entonces, pero manteniéndose, respecto al inicio del período contemplado, una cifra superior al 30\%. Similar evolución sigue la ratio depósitos por habitante, que pasa de 18 mil euros a 30 mil, alcanzando un punto máximo en 2008, con 35 mil. En cambio el ajuste vivido en los últimos años en el número de oficinas, unido al ya destacado incremento de los depósitos, ha hecho que el nivel máximo de la ratio se logre en el último año (2012), con 36,7 millones de euros, frente a los pocos más de 19 en 2002.

En cuanto a los préstamos, la evolución de sus ratios respecto al PIB y al número de habitantes es similar a las de los depósitos, con aumentos absolutos en el final respecto al inicio del período, pero con puntos máximos que se producen en 2008-2009. En cambio, la caída en la actividad económica, y en especial en el volumen de préstamos concedidos hace que prácticamente la ratio se mantenga estable alrededor de 43-45 millones de euros durante la crisis, mientras que esa cifra había aumentado de forma espectacular en el período anterior (desde los 19,2 millones de euros en 2002 hasta 43 millones en 2008).

Comparando ahora los datos correspondientes a las entidades bancarias españolas respecto a los de los países que han recibido apoyo público para el saneamiento de su sector financiero, podemos comprobar, en primer lugar, en la Tabla 4, relativa a los indicadores de presencia y tamaño de las entidades bancarias $^{27}$, que en todos los países considerados se ha producido una reducción continua en el número de entidades, acompañada de un incremento en el grado de concentración bancaria, que no es sólo una respuesta a la crisis iniciada en 2007, sino que ya se venía percibiendo en todos ellos desde principios de la década, si bien esa concentración de la actividad se intensifica en los últimos años como consecuencia de la conjunción de dos factores: por una parte, que las entidades de mayor tamaño han entrado en procesos de fusiones o absorciones de entidades más pequeñas; y por otra, por los propios movimientos de la clientela hacia las mayores, buscando una mayor seguridad para sus recursos en períodos de fuerte inestabilidad. Este aumento de la concentración es más evi-

\footnotetext{
${ }^{27}$ En realidad los datos no están referidos a las entidades del sistema bancario de cada uno de los países, sino en realidad a las de crédito, que es una denominación más homogénea y que facilita pues las comparaciones que realizamos.
} 
dente desde 2007 en Alemania, Grecia e Irlanda, con alrededor de 12 puntos ${ }^{28}$, siendo menor en España con 5. En cambio, si tomamos como referencia todo el período contemplado en la tabla, la variación de la concentración es muy acusada, de más de 10 puntos en todos los países, a excepción de España, con menos de 8, y de Chipre, con menos de 5; siendo muy representativo el cambio en Estados Unidos, con un aumento de más de 20 puntos.

\section{Tabla 4}

Indicadores de presencia y tamaño bancario (2002-2012)

\begin{tabular}{|c|c|c|c|c|c|c|c|c|c|c|c|}
\hline & 2002 & 2003 & 2004 & 2005 & 2006 & 2007 & 2008 & 2009 & 2010 & 2011 & 2012 \\
\hline $\begin{array}{l}\text { ESPAÑA } \\
\text { Número de entidades } \\
\text { Activos/Entidad (Mill.€) } \\
\text { Activos/PIB (\%) } \\
\text { Activos/Habitante (Mill.€) } \\
\text { Concentración (*) }\end{array}$ & $\begin{array}{r}361 \\
3.722,10 \\
184,25 \\
0,032 \\
43,50\end{array}$ & \begin{tabular}{|r|}
350 \\
$4.294,46$ \\
191,94 \\
0,035 \\
43,10
\end{tabular} & $\begin{array}{r}348 \\
4.933,65 \\
204,08 \\
0,040 \\
41,90\end{array}$ & \begin{tabular}{|r|}
350 \\
$6.079,43$ \\
234,00 \\
0,048 \\
42,00
\end{tabular} & $\begin{array}{r}355 \\
6.981,83 \\
251,49 \\
0,055 \\
40,40\end{array}$ & $\begin{array}{r}358 \\
8.081,51 \\
274,71 \\
0,063 \\
41,00\end{array}$ & \begin{tabular}{|r|}
361 \\
$8.703,48$ \\
288,84 \\
0,068 \\
42,40
\end{tabular} & $\begin{array}{r}353 \\
8.900,93 \\
299,79 \\
0,068 \\
43,30\end{array}$ & \begin{tabular}{|r|}
339 \\
$9.209,04$ \\
297,64 \\
0,067 \\
44,30
\end{tabular} & $\begin{array}{r}336 \\
9.437,28 \\
298,20 \\
0,068 \\
48,10\end{array}$ & $\begin{array}{r}312 \\
9.969,55 \\
296,37 \\
0,067 \\
51,40\end{array}$ \\
\hline $\begin{array}{l}\text { ALEMANIA } \\
\text { Número de entidades } \\
\text { Activos/Entidad (Mill.€) } \\
\text { Activos/PIB (\%) } \\
\text { Activos/Habitante (Mill.€) } \\
\text { Concentración }\left(^{*}\right)\end{array}$ & $\begin{array}{r}2.365 \\
2.728,24 \\
302,61 \\
0,078 \\
20,45\end{array}$ & \begin{tabular}{|r|}
2.226 \\
$2.907,10$ \\
301,34 \\
0,078 \\
21,63
\end{tabular} & \begin{tabular}{|r|}
2.147 \\
$3.103,77$ \\
303,49 \\
0,081 \\
22,15
\end{tabular} & \begin{tabular}{|r|}
2.089 \\
$3.304,55$ \\
310,34 \\
0,084 \\
21,63
\end{tabular} & \begin{tabular}{|r|}
2.048 \\
$3.510,50$ \\
310,71 \\
0,087 \\
21,99
\end{tabular} & $\begin{array}{r}2.015 \\
3.784,47 \\
314,01 \\
0,093 \\
22,00\end{array}$ & $\begin{array}{r}1.981 \\
4.016,30 \\
321,62 \\
0,097 \\
22,74\end{array}$ & $\begin{array}{r}1.939 \\
3.873,03 \\
316,31 \\
0,092 \\
25,01\end{array}$ & \begin{tabular}{|r|}
1.919 \\
$4.353,36$ \\
334,83 \\
0,102 \\
32,60
\end{tabular} & $\begin{array}{r}1.903 \\
4.448,92 \\
324,39 \\
0,105 \\
33,55\end{array}$ & $\begin{array}{r}1.869 \\
4.448,69 \\
311,83 \\
0,103 \\
33,00\end{array}$ \\
\hline $\begin{array}{l}\text { GRECIA } \\
\text { Número de entidades } \\
\text { Activos/Entidad (Mill.€) } \\
\text { Activos/PIB (\%) } \\
\text { Activos/Habitante (Mill.€) } \\
\text { Concentración (*) }\end{array}$ & \begin{tabular}{|r|}
60 \\
$3.360,17$ \\
128,73 \\
0,018 \\
67,40
\end{tabular} & \begin{tabular}{|r|}
59 \\
$3.613,03$ \\
123,62 \\
0,019 \\
66,90
\end{tabular} & \begin{tabular}{|r|}
62 \\
$3.717,00$ \\
124,39 \\
0,021 \\
65,00
\end{tabular} & \begin{tabular}{|r|}
61 \\
$4.607,64$ \\
145,59 \\
0,025 \\
65,60
\end{tabular} & \begin{tabular}{|r|}
62 \\
$5.081,97$ \\
151,03 \\
0,028 \\
66,30
\end{tabular} & $\begin{array}{r}65 \\
5.896,83 \\
171,76 \\
0,034 \\
67,70\end{array}$ & \begin{tabular}{|r|}
66 \\
$6.999,74$ \\
198,11 \\
0,041 \\
69,50
\end{tabular} & \begin{tabular}{|r|}
66 \\
$7.426,32$ \\
212,11 \\
0,044 \\
69,19
\end{tabular} & \begin{tabular}{|r}
62 \\
$8.286,81$ \\
231,27 \\
0,046 \\
70,64
\end{tabular} & $\begin{array}{r}58 \\
8.209,81 \\
228,34 \\
0,043 \\
71,99\end{array}$ & $\begin{array}{r}52 \\
8.487,96 \\
227,80 \\
0,040 \\
79,47\end{array}$ \\
\hline $\begin{array}{l}\text { IRLANDA } \\
\text { Número de entidades } \\
\text { Activos/Entidad (Mill.€) } \\
\text { Activos/PIB (\%) } \\
\text { Activos/Habitante (Mill.€) } \\
\text { Concentración (*) }\end{array}$ & $\begin{array}{r}86 \\
5.518,93 \\
363,10 \\
0,112 \\
46,09\end{array}$ & \begin{tabular}{|r|}
80 \\
$7.189,60$ \\
408,98 \\
0,143 \\
44,42
\end{tabular} & \begin{tabular}{|r|}
80 \\
$8.622,46$ \\
459,79 \\
0,168 \\
45,89
\end{tabular} & \begin{tabular}{|r|}
79 \\
$11.169,8$ \\
541,70 \\
0,210 \\
47,78
\end{tabular} & \begin{tabular}{|r|}
79 \\
$13.826,5$ \\
615,12 \\
0,252 \\
48,96
\end{tabular} & \begin{tabular}{|r|}
82 \\
$15.485,0$ \\
669,51 \\
0,285 \\
50,39
\end{tabular} & \begin{tabular}{|r|}
81 \\
$17.856,3$ \\
802,42 \\
0,325 \\
55,34
\end{tabular} & $\begin{array}{r}82 \\
15.889,4 \\
802,87 \\
0,286 \\
58,76\end{array}$ & $\begin{array}{r}78 \\
14.974,5 \\
738,79 \\
0,255 \\
56,84\end{array}$ & \begin{tabular}{|r|}
77 \\
$13.312,6$ \\
630,42 \\
0,224 \\
53,21
\end{tabular} & $\begin{array}{r}70 \\
12.466,8 \\
532,30 \\
0,190 \\
56,88\end{array}$ \\
\hline $\begin{array}{l}\text { PORTUGAL } \\
\text { Número de entidades } \\
\text { Activos/Entidad (Mill.€) } \\
\text { Activos/PIB (\%) } \\
\text { Activos/Habitante (Mill.€) } \\
\text { Concentración }\left(^{*}\right)\end{array}$ & $\begin{array}{r}266 \\
1.063,89 \\
201,32 \\
0,027 \\
60,47\end{array}$ & \begin{tabular}{|r|}
254 \\
$1.197,11$ \\
211,93 \\
0,029 \\
62,72
\end{tabular} & \begin{tabular}{|r|}
246 \\
$1.107,36$ \\
182,44 \\
0,026 \\
66,54
\end{tabular} & $\begin{array}{r}235 \\
1.302,08 \\
198,35 \\
0,029 \\
68,77\end{array}$ & $\begin{array}{r}227 \\
1.489,30 \\
210,17 \\
0,032 \\
67,93\end{array}$ & \begin{tabular}{|r|}
223 \\
$1.988,60$ \\
261,91 \\
0,042 \\
67,81
\end{tabular} & \begin{tabular}{|r|}
223 \\
$2.138,49$ \\
277,28 \\
0,045 \\
69,10
\end{tabular} & $\begin{array}{r}213 \\
2.397,12 \\
302,97 \\
0,048 \\
70,15\end{array}$ & $\begin{array}{r}207 \\
2.568,70 \\
307,60 \\
0,050 \\
70,88\end{array}$ & $\begin{array}{r}200 \\
2.563,05 \\
299,68 \\
0,049 \\
70,75\end{array}$ & $\begin{array}{r}197 \\
2.515,56 \\
299,89 \\
0,047 \\
69,95\end{array}$ \\
\hline $\begin{array}{l}\text { CHIPRE } \\
\text { Número de entidades } \\
\text { Activos/Entidad (Mill.€) } \\
\text { Activos/PIB (\%) } \\
\text { Activos/Habitante (Mill.€) } \\
\text { Concentración (*) }\end{array}$ & $\begin{array}{r}410 \\
83,29 \\
308,18 \\
0,048 \\
57,80\end{array}$ & $\begin{array}{r}409 \\
87,41 \\
306,76 \\
0,049 \\
57,20\end{array}$ & $\begin{array}{r}406 \\
89,36 \\
288,03 \\
0,049 \\
57,35\end{array}$ & $\begin{array}{r}392 \\
159,57 \\
460,01 \\
0,084 \\
59,79\end{array}$ & $\begin{array}{r}338 \\
226,69 \\
522,29 \\
0,101 \\
63,93\end{array}$ & $\begin{array}{r}217 \\
428,10 \\
584,20 \\
0,120 \\
64,90\end{array}$ & $\begin{array}{r}165 \\
716,01 \\
688,59 \\
0,148 \\
63,81\end{array}$ & $\begin{array}{r}157 \\
887,72 \\
826,96 \\
0,170 \\
64,88\end{array}$ & $\begin{array}{r}153 \\
882,12 \\
775,39 \\
0,161 \\
64,16\end{array}$ & $\begin{array}{r}143 \\
937,14 \\
745,36 \\
0,155 \\
60,76\end{array}$ & $\begin{array}{r}138 \\
928,46 \\
716,32 \\
0,148 \\
62,50\end{array}$ \\
\hline $\begin{array}{l}\text { ISLANDIA } \\
\text { Número de entidades } \\
\text { Activos/Entidad (Mill.€) } \\
\text { Activos/PIB (\%) } \\
\text { Activos/Habitante (Mill.€) } \\
\text { Concentración (*) }\end{array}$ & $\begin{array}{r}38 \\
229,40 \\
92,01 \\
0,030 \\
73,82\end{array}$ & $\begin{array}{r}37 \\
302,53 \\
115,26 \\
0,038 \\
81,60\end{array}$ & $\begin{array}{r}37 \\
584,37 \\
202,56 \\
0,074 \\
86,44\end{array}$ & $\begin{array}{r}38 \\
1.039,09 \\
301,14 \\
0,132 \\
86,39\end{array}$ & \begin{tabular}{|r|}
36 \\
$1.703,62$ \\
460,58 \\
0,199 \\
86,99
\end{tabular} & $\begin{array}{r}36 \\
2.337,01 \\
563,42 \\
0,267 \\
84,96\end{array}$ & $\begin{array}{r}34 \\
3.494,20 \\
1154,29 \\
0,372 \\
\text { n.d. }\end{array}$ & $\begin{array}{r}27 \\
781,38 \\
243,20 \\
0,066 \\
75,67\end{array}$ & $\begin{array}{r}24 \\
819,98 \\
207,43 \\
0,062 \\
82,45\end{array}$ & $\begin{array}{r}22 \\
905,94 \\
197,14 \\
0,062 \\
89,19\end{array}$ & $\begin{array}{r}19 \\
1.038,52 \\
185,67 \\
0,061 \\
89,62\end{array}$ \\
\hline
\end{tabular}

${ }^{28}$ En Islandia ese aumento de la concentración de su actividad bancaria es de 14 puntos, comparado al año 2009, si bien la cifra de 2011-2012 se mueve en parámetros no muy alejados de los que alcanzó 2004-2006. 
Tabla 4 (continuación)

Indicadores de presencia y tamaño bancario

(2002-2012)

\begin{tabular}{|l|r|r|r|r|r|r|r|r|r|r|r|}
\hline & $\mathbf{2 0 0 2}$ & $\mathbf{2 0 0 3}$ & $\mathbf{2 0 0 4}$ & $\mathbf{2 0 0 5}$ & \multicolumn{1}{|c|}{$\mathbf{2 0 0 6}$} & $\mathbf{2 0 0 7}$ & $\mathbf{2 0 0 8}$ & $\mathbf{2 0 0 9}$ & $\mathbf{2 0 1 0}$ & $\mathbf{2 0 1 1}$ & $\mathbf{2 0 1 2}$ \\
\hline ESTADOS UNIDOS & & & & & & & & & & & \\
Número de entidades & 19.042 & 18.550 & 17.990 & 17.528 & 17.042 & 16.635 & 16.111 & 15.566 & 14.997 & 14.451 & 13.902 \\
Activos/Entidad (Mill.€) & 365,00 & 403,55 & 462,01 & 509,58 & 570,12 & 640,56 & 703,57 & 693,69 & 733,50 & 794,41 & 860,18 \\
Activos/PIB (\%) & 59,85 & 73,56 & 84,21 & 84,86 & 88,03 & 100,85 & 113,26 & 104,46 & 97,49 & 102,87 & 94,58 \\
Activos/Habitante (Mill.€) & 0,024 & 0,026 & 0,028 & 0,030 & 0,032 & 0,035 & 0,037 & 0,035 & 0,035 & 0,037 & 0,038 \\
Concentración (*) & 19,18 & 21,53 & 29,66 & 31,81 & 34,29 & 36,30 & 38,31 & 38,46 & 32,10 & 40,68 & 40,69 \\
\hline
\end{tabular}

(*) Calculada por la cuota de mercado (\% de activos totales canalizados) de los cinco principales grupos bancarios, excepto en Islandia, que está medida por la cuota de mercado de los tres principales grupos bancarios, puesto que en este país sólo operan, actualmente, cuatro bancos comerciales.

Fuente: Elaboración propia a partir de los datos suministrados por "Banco Central Europeo", "Financial Supervisory Authority of Iceland", "Federal Deposit Insurance Corporation" y "Eurostat".

La ratio volumen de activos por entidad refleja un aumento en todos los países, salvo en Irlanda, cuyo nivel se sitúa en cifras anteriores al inicio de la crisis financiera. Ese aumento general se produce como consecuencia fundamentalmente de que ese volumen ha tenido una caída relativa inferior al del número de entidades, permitiendo pues una recuperación de la ratio. El cálculo del volumen de activos respecto al PIB de cada país está marcado ahora por la evolución de esta última variable, pues la caída en el crecimiento en países como España o Grecia, ha permitido que la ratio aumente más de 20 puntos porcentuales en el primero (aunque se mantiene muy estable desde 2009) y más de 50 en el segundo desde 2007, mientras que en el resto se deteriora de forma moderada en general, aunque, en algunos casos, como en el de Islandia, de forma significativa.

En la Tabla 5 recogemos, en segundo lugar, algunos indicadores de servicio bancario, en los que observamos una evolución decreciente, similar en cuanto al número de oficinas y de empleados (excepto en Chipre, en el que la cifra se mantiene relativamente estable durante todo el período de la crisis), que unido a la ya destacada concentración de la actividad bancaria, propiciada en parte por la reducción de entidades, configura un ajuste en el sector bancario de todos los países. Resulta significativa, por otra parte, la reducción que en general se observa en la ratio empleados por oficina (salvo en España, Alemania y Chipre), lo que se explica por el mayor ajuste relativo de la plantilla, siendo más apreciable este fenómeno en países como Irlanda e Islandia. A pesar del aumento de esa ratio en nuestro país, las entidades bancarias españolas se caracterizan por tener unas sucursales de reducido tamaño, pues el número de empleados medio es de poco más de 6 , lo que contrasta con todos los demás, quedando más cerca Portugal, con algo más de 9 empleados por oficina bancaria. Por último, la reducción en el número de oficinas y de empleados marca la evolución de las ratios correspondientes a su relación en función de los habitantes del país, pues la tónica general es la disminución de ambas ratios desde el inicio de la crisis. 
Tabla 5

Indicadores de servicio bancario

(2002-2012)

\begin{tabular}{|c|c|c|c|c|c|c|c|c|c|c|c|}
\hline & 2002 & 2003 & 2004 & 2005 & 2006 & 2007 & 2008 & 2009 & 2010 & 2011 & 2012 \\
\hline $\begin{array}{l}\text { ESPAÑA } \\
\text { Número de oficinas } \\
\text { Número de empleados } \\
\text { Empleados/Oficina } \\
\text { Oficinas/10.000 habitantes } \\
\text { Empleados } / 1.000 \text { habitantes }\end{array}$ & \begin{tabular}{|r|}
39.059 \\
243.429 \\
6,23 \\
9,34 \\
5,82
\end{tabular} & \begin{tabular}{|r|}
39.799 \\
243.462 \\
6,12 \\
9,35 \\
5,72 \\
\end{tabular} & \begin{tabular}{|r}
40.656 \\
246.236 \\
6,06 \\
9,39 \\
5,69 \\
\end{tabular} & $\begin{array}{r}42.036 \\
252.831 \\
6,01 \\
9,55 \\
5,74 \\
\end{array}$ & $\begin{array}{r}43.753 \\
261.890 \\
5,99 \\
9,77 \\
5,85 \\
\end{array}$ & \begin{tabular}{|r}
45.571 \\
275.506 \\
6,05 \\
9,98 \\
6,03
\end{tabular} & \begin{tabular}{|r|}
46.143 \\
276.497 \\
5,99 \\
9,98 \\
5,98 \\
\end{tabular} & \begin{tabular}{|r|}
44.512 \\
267.383 \\
6,01 \\
9,57 \\
5,75 \\
\end{tabular} & \begin{tabular}{|r}
43.244 \\
261.389 \\
6,04 \\
9,27 \\
5,60
\end{tabular} & $\begin{array}{r}40.182 \\
245.956 \\
6,12 \\
8,58 \\
5,25\end{array}$ & $\begin{array}{r}38.219 \\
234.292 \\
6,13 \\
8,18 \\
5,02\end{array}$ \\
\hline $\begin{array}{l}\text { ALEMANIA } \\
\text { Número de oficinas } \\
\text { Número de empleados } \\
\text { Empleados/Oficina } \\
\text { Oficinas/10.000 habitantes } \\
\text { Empleados/1.000 habitantes }\end{array}$ & $\begin{array}{r}35.340 \\
717.150 \\
20,29 \\
4,28 \\
8,69 \\
\end{array}$ & $\begin{array}{r}33.753 \\
690.350 \\
20,45 \\
4,09 \\
8,36 \\
\end{array}$ & $\begin{array}{r}42.659 \\
678.800 \\
15,91 \\
5,17 \\
8,23 \\
\end{array}$ & \begin{tabular}{|r|}
41.362 \\
672.500 \\
16,26 \\
5,02 \\
8,16 \\
\end{tabular} & $\begin{array}{r}38.487 \\
662.200 \\
17,20 \\
4,68 \\
8,04 \\
\end{array}$ & $\begin{array}{r}37.976 \\
662.650 \\
17,45 \\
4,62 \\
8,06 \\
\end{array}$ & \begin{tabular}{|r|}
37.659 \\
657.850 \\
17,47 \\
4,59 \\
8,02 \\
\end{tabular} & $\begin{array}{r}36.927 \\
646.650 \\
17,51 \\
4,51 \\
7,90 \\
\end{array}$ & $\begin{array}{r}36.463 \\
642.050 \\
17,61 \\
4,46 \\
7,85 \\
\end{array}$ & $\begin{array}{r}36.027 \\
637.700 \\
17,70 \\
4,40 \\
7,79 \\
\end{array}$ & \begin{tabular}{|r}
34.571 \\
633.650 \\
18,33 \\
4,29 \\
7,87 \\
\end{tabular} \\
\hline $\begin{array}{l}\text { GRECIA } \\
\text { Número de oficinas } \\
\text { Número de empleados } \\
\text { Empleados/Oficina } \\
\text { Oficinas/10.000 habitantes } \\
\text { Empleados/1.000 habitantes }\end{array}$ & $\begin{array}{r}3.277 \\
60.495 \\
18,46 \\
2,98 \\
5,50\end{array}$ & $\begin{array}{r}3.314 \\
61.074 \\
18,43 \\
3,00 \\
5,53\end{array}$ & $\begin{array}{r}3.422 \\
59.337 \\
17,34 \\
3,09 \\
5,36\end{array}$ & $\begin{array}{r}3.562 \\
61.295 \\
17,21 \\
3,21 \\
5,52\end{array}$ & $\begin{array}{r}3.719 \\
62.171 \\
16,72 \\
3,34 \\
5,58\end{array}$ & $\begin{array}{r}3.872 \\
64.713 \\
16,71 \\
3,46 \\
5,79\end{array}$ & $\begin{array}{r}4.122 \\
66.163 \\
16,04 \\
3,68 \\
5,91\end{array}$ & $\begin{array}{r}4.102 \\
65.673 \\
16,01 \\
3,67 \\
5,87\end{array}$ & $\begin{array}{r}4.026 \\
63.408 \\
15,75 \\
3,62 \\
5,70\end{array}$ & $\begin{array}{r}3.866 \\
59.958 \\
15,51 \\
3,48 \\
5,39\end{array}$ & $\begin{array}{r}3.647 \\
57.006 \\
15,63 \\
3,30 \\
5,15\end{array}$ \\
\hline $\begin{array}{l}\text { IRLANDA } \\
\text { Número de oficinas } \\
\text { Número de empleados } \\
\text { Empleados/Oficina } \\
\text { Oficinas/10.000 habitantes } \\
\text { Empleados/1.000 habitantes }\end{array}$ & $\begin{array}{r}957 \\
36.585 \\
38,23 \\
2,41 \\
9,23\end{array}$ & $\begin{array}{r}955 \\
35.658 \\
37,34 \\
2,37 \\
8,85\end{array}$ & $\begin{array}{r}940 \\
35.564 \\
37,83 \\
2,29 \\
8,65\end{array}$ & $\begin{array}{r}941 \\
37.702 \\
40,07 \\
2,24 \\
8,96 \\
\end{array}$ & $\begin{array}{r}966 \\
39.154 \\
40,53 \\
2,24 \\
9,08\end{array}$ & $\begin{array}{r}1.189 \\
41.865 \\
35,21 \\
2,70 \\
9,51 \\
\end{array}$ & $\begin{array}{r}926 \\
40.507 \\
43,74 \\
2,08 \\
9,10\end{array}$ & $\begin{array}{r}1.260 \\
38.178 \\
30,30 \\
2,82 \\
8,54\end{array}$ & $\begin{array}{r}1.195 \\
36.438 \\
30,49 \\
2,61 \\
7,97\end{array}$ & $\begin{array}{r}1.136 \\
35.612 \\
31,35 \\
2,48 \\
7,77\end{array}$ & $\begin{array}{r}1.099 \\
31.776 \\
28,91 \\
2,39 \\
6,92\end{array}$ \\
\hline $\begin{array}{l}\text { PORTUGAL } \\
\text { Número de oficinas } \\
\text { Número de empleados } \\
\text { Empleados/Oficina } \\
\text { Oficinas/10.000 habitantes } \\
\text { Empleados/1.000 habitantes }\end{array}$ & $\begin{array}{r}5.369 \\
55.679 \\
10,37 \\
5,14 \\
5,33\end{array}$ & $\begin{array}{r}5.419 \\
54.350 \\
10,03 \\
5,17 \\
5,19\end{array}$ & $\begin{array}{r}5.397 \\
53.230 \\
9,86 \\
5,14 \\
5,07\end{array}$ & $\begin{array}{r}5.446 \\
54.035 \\
9,92 \\
5,18 \\
5,14\end{array}$ & $\begin{array}{r}5.641 \\
58.213 \\
10,32 \\
5,36 \\
5,53\end{array}$ & $\begin{array}{r}6.078 \\
60.979 \\
10,03 \\
5,76 \\
5,78\end{array}$ & $\begin{array}{r}6.442 \\
62.377 \\
9,68 \\
6,10 \\
5,90\end{array}$ & $\begin{array}{r}6.557 \\
61.593 \\
9,39 \\
6,20 \\
5,82\end{array}$ & $\begin{array}{r}6.611 \\
61.504 \\
9,30 \\
6,25 \\
5,82\end{array}$ & $\begin{array}{r}6.523 \\
59.911 \\
9,18 \\
6,19 \\
5,68\end{array}$ & $\begin{array}{r}6.280 \\
57.346 \\
9,13 \\
5,99 \\
5,47\end{array}$ \\
\hline $\begin{array}{l}\text { CHIPRE } \\
\text { Número de oficinas } \\
\text { Número de empleados } \\
\text { Empleados/Oficina } \\
\text { Oficinas/10.000 habitantes } \\
\text { Empleados } / 1.000 \text { habitantes }\end{array}$ & $\begin{array}{r}998 \\
10.613 \\
10,63 \\
13,95 \\
14,84 \\
\end{array}$ & $\begin{array}{r}988 \\
10.480 \\
10,61 \\
13,53 \\
14,35 \\
\end{array}$ & $\begin{array}{r}981 \\
10.617 \\
10,82 \\
13,09 \\
14,17 \\
\end{array}$ & $\begin{array}{r}955 \\
10.799 \\
11,31 \\
12,46 \\
14,09 \\
\end{array}$ & $\begin{array}{r}945 \\
10.845 \\
11,48 \\
12,14 \\
13,93 \\
\end{array}$ & $\begin{array}{r}930 \\
11.286 \\
12,13 \\
11,78 \\
14,30 \\
\end{array}$ & $\begin{array}{r}931 \\
12.554 \\
13,48 \\
11,68 \\
15,75 \\
\end{array}$ & $\begin{array}{r}939 \\
12.513 \\
13,33 \\
11,46 \\
15,28 \\
\end{array}$ & $\begin{array}{r}920 \\
12.643 \\
13,74 \\
10,96 \\
15,06 \\
\end{array}$ & $\begin{array}{r}911 \\
12.825 \\
14,08 \\
10,57 \\
14,88 \\
\end{array}$ & $\begin{array}{r}877 \\
12.853 \\
14,66 \\
10,06 \\
14,74 \\
\end{array}$ \\
\hline $\begin{array}{l}\text { ISLANDIA } \\
\text { Número de oficinas } \\
\text { Número de empleados } \\
\text { Empleados/Oficina } \\
\text { Oficinas/10.000 habitantes } \\
\text { Empleados/1.000 habitantes }\end{array}$ & $\begin{array}{r}198 \\
3.733 \\
18,85 \\
6,86 \\
12,94\end{array}$ & $\begin{array}{r}183 \\
3.480 \\
19,02 \\
6,30 \\
11,98\end{array}$ & $\begin{array}{r}158 \\
4.493 \\
28,44 \\
5,38 \\
15,30\end{array}$ & $\begin{array}{r}171 \\
4.001 \\
23,40 \\
5,70 \\
13,34\end{array}$ & $\begin{array}{r}164 \\
7.292 \\
44,46 \\
5,33 \\
23,70\end{array}$ & $\begin{array}{r}94 \\
4.114 \\
43,77 \\
2,98 \\
13,04\end{array}$ & $\begin{array}{r}152 \\
4.245 \\
27,93 \\
4,76 \\
13,29\end{array}$ & $\begin{array}{r}129 \\
3.610 \\
27,98 \\
4,06 \\
11,36\end{array}$ & $\begin{array}{l}\text { n.d. } \\
\text { n.d. } \\
\text { n.d. } \\
\text { n.d. } \\
\text { n.d. }\end{array}$ & $\begin{array}{l}\text { n.d. } \\
\text { n.d. } \\
\text { n.d. } \\
\text { n.d. } \\
\text { n.d. }\end{array}$ & $\begin{array}{l}\text { n.d. } \\
\text { n.d. } \\
\text { n.d. } \\
\text { n.d. } \\
\text { n.d. }\end{array}$ \\
\hline $\begin{array}{l}\text { ESTADOS UNIDOS } \\
\text { Número de oficinas } \\
\text { Número de empleados } \\
\text { Empleados/Oficina } \\
\text { Oficinas/10.000 habitantes } \\
\text { Empleados/1.000 habitantes }\end{array}$ & $\begin{array}{r}88.766 \\
.017 .645 \\
22,73 \\
3,08 \\
7,00\end{array}$ & \begin{tabular}{|r|}
90.061 \\
.045 .975 \\
22,72 \\
3,10 \\
7,03
\end{tabular} & $\begin{array}{r}92.639 \\
.097 .165 \\
22,64 \\
3,16 \\
7,15\end{array}$ & $\begin{array}{r}94.841 \\
.150 .741 \\
22,68 \\
3,20 \\
7,26\end{array}$ & \begin{tabular}{|r|}
97.270 \\
206.648 \\
22,69 \\
3,25 \\
7,38
\end{tabular} & \begin{tabular}{|r|}
99.221 \\
.215 .029 \\
22,32 \\
3,28 \\
7,33
\end{tabular} & $\begin{array}{r}100.471 \\
151.758 \\
21,42 \\
3,30 \\
7,06\end{array}$ & \begin{tabular}{|r|}
101.130 \\
.063 .107 \\
20,40 \\
3,29 \\
6,71
\end{tabular} & \begin{tabular}{|r|}
100.023 \\
.086 .582 \\
20,86 \\
3,22 \\
6,73
\end{tabular} & \begin{tabular}{|r|}
99.600 \\
108.565 \\
21,17 \\
3,18 \\
6,73
\end{tabular} & \begin{tabular}{|r}
98.786 \\
110.276 \\
21,36 \\
3,16 \\
6,75
\end{tabular} \\
\hline
\end{tabular}

Nota: n.d. (no disponible).

Fuente: Elaboración propia a partir de los datos suministrados por "Banco Central Europeo", "Financial Supervisory Authority of Iceland", "American Bankers' Association" y "Eurostat".

Finalmente, a partir de la Tabla 6 podemos realizar una comparativa de los indicadores de operativa bancaria. De su contenido podemos destacar la caída en general de las ratios de los depósitos y de los préstamos en relación al PIB, 
salvo en Portugal en el primero, y de Chipre en el segundo. Calculada la ratio de depósitos respecto al número de habitantes, la evolución general es negativa, salvo en Portugal, Estados Unidos y Alemania, siendo espectacular la caída en Irlanda e Islandia, y algo menos en Chipre. En cambio, la relación entre el volumen de préstamos concedidos en relación a la población se mantiene relativamente estable en Estados Unidos, Islandia (si bien esto se produce en los tres últimos años considerados, pues antes se produjo una caída muy importante en la ratio), Portugal, Grecia y Alemania, cayendo en España (más de 7 mil euros por habitante desde 2008) y, sobre todo, en Irlanda.

Tabla 6

Indicadores de operativa bancaria (2002-2012)

\begin{tabular}{|c|c|c|c|c|c|c|c|c|c|c|c|}
\hline & 002 & 2003 & 2004 & 2005 & 2006 & 2007 & 2008 & 2009 & 2010 & 2011 & 2012 \\
\hline $\begin{array}{l}\text { ESPAÑA } \\
\text { Depósitos/PIB (\%) } \\
\text { Depósitos/Habitante (Mill.€) } \\
\text { Depósitos/Oficina (Mill.€) } \\
\text { Préstamos/PIB (\%) } \\
\text { Préstamos/Habitante (Mill.€) } \\
\text { Préstamos/Oficina (Mill.€) }\end{array}$ & $\begin{array}{r}103,04 \\
0,018 \\
19,24 \\
102,90 \\
0,018 \\
19,21 \\
\end{array}$ & $\begin{array}{r}103,10 \\
0,019 \\
20,29 \\
108,05 \\
0,020 \\
21,26 \\
\end{array}$ & $\begin{array}{r}108,17 \\
0,021 \\
22,38 \\
121,55 \\
0,024 \\
25,15 \\
\end{array}$ & $\begin{array}{r}118,65 \\
0,024 \\
25,67 \\
139,22 \\
0,029 \\
30,12 \\
\end{array}$ & $\begin{array}{r}131,32 \\
0,029 \\
29,58 \\
161,80 \\
0,036 \\
36,45 \\
\end{array}$ & $\begin{array}{r}139,36 \\
0,032 \\
32,21 \\
176,67 \\
0,041 \\
40,83 \\
\end{array}$ & $\begin{array}{r}147,63 \\
0,035 \\
34,80 \\
182,55 \\
0,043 \\
43,03 \\
\end{array}$ & $\begin{array}{r}151,27 \\
0,034 \\
35,62 \\
184,44 \\
0,042 \\
43,43 \\
\end{array}$ & $\begin{array}{r}148,58 \\
0,033 \\
36,04 \\
182,14 \\
0,041 \\
44,18 \\
\end{array}$ & $\begin{array}{r}137,40 \\
0,031 \\
36,36 \\
173,04 \\
0,039 \\
45,79 \\
\end{array}$ & $\begin{array}{r}133,63 \\
0,030 \\
36,70 \\
154,21 \\
0,035 \\
42,35 \\
\end{array}$ \\
\hline $\begin{array}{l}\text { ALEMANIA } \\
\text { Depósitos/PIB (\%) } \\
\text { Depósitos/Habitante (Mill.€) } \\
\text { Depósitos/Oficina (Mill.€) } \\
\text { Préstamos/PIB (\%) } \\
\text { Préstamos/Habitante (Mill.€) } \\
\text { Préstamos/Oficina (Mill.€) } \\
\end{array}$ & $\begin{array}{r}112,80 \\
0,029 \\
68,06 \\
166,78 \\
0,043 \\
100,62 \\
\end{array}$ & $\begin{array}{r}113,97 \\
0,030 \\
72,51 \\
166,33 \\
0,043 \\
105,82 \\
\end{array}$ & $\begin{array}{r}114,37 \\
0,030 \\
58,87 \\
165,36 \\
0,044 \\
85,11 \\
\end{array}$ & $\begin{array}{r}116,57 \\
0,031 \\
62,69 \\
166,65 \\
0,045 \\
89,62 \\
\end{array}$ & $\begin{array}{r}116,89 \\
0,033 \\
70,28 \\
163,26 \\
0,046 \\
98,16 \\
\end{array}$ & $\begin{array}{r}118,83 \\
0,035 \\
75,89 \\
159,94 \\
0,047 \\
102,28 \\
\end{array}$ & $\begin{array}{r}123,99 \\
0,037 \\
81,45 \\
160,86 \\
0,048 \\
105,67 \\
\end{array}$ & $\begin{array}{r}128,29 \\
0,037 \\
82,48 \\
164,93 \\
0,048 \\
106,04 \\
\end{array}$ & $\begin{array}{r}126,78 \\
0,039 \\
86,75 \\
160,18 \\
0,049 \\
109,60 \\
\end{array}$ & $\begin{array}{r}125,35 \\
0,041 \\
90,80 \\
151,03 \\
0,049 \\
109,41 \\
\end{array}$ & $\begin{array}{r}124,80 \\
0,041 \\
96,26 \\
148,11 \\
0,049 \\
114,23 \\
\end{array}$ \\
\hline $\begin{array}{l}\text { GRECIA } \\
\text { Depósitos/PIB (\%) } \\
\text { Depósitos/Habitante (Mill.€) } \\
\text { Depósitos/Oficina (Mill.€) } \\
\text { Préstamos/PIB (\%) } \\
\text { Préstamos/Habitante (Mill.€) } \\
\text { Préstamos/Oficina (Mill.€) }\end{array}$ & $\begin{array}{r}103,04 \\
0,012 \\
40,84 \\
102,90 \\
0,009 \\
29,02 \\
\end{array}$ & $\begin{array}{r}103,10 \\
0,013 \\
42,25 \\
108,05 \\
0,010 \\
33,20 \\
\end{array}$ & $\begin{array}{r}108,17 \\
0,014 \\
46,71 \\
121,55 \\
0,011 \\
37,30 \\
\end{array}$ & $\begin{array}{r}118,65 \\
0,017 \\
52,66 \\
139,22 \\
0,014 \\
42,92 \\
\end{array}$ & $\begin{array}{r}131,32 \\
0,019 \\
56,86 \\
161,80 \\
0,015 \\
46,38 \\
\end{array}$ & $\begin{array}{r}139,36 \\
0,022 \\
64,23 \\
176,67 \\
0,018 \\
52,81 \\
\end{array}$ & $\begin{array}{r}147,63 \\
0,025 \\
68,02 \\
182,55 \\
0,020 \\
54,83 \\
\end{array}$ & $\begin{array}{r}151,27 \\
0,025 \\
68,15 \\
184,44 \\
0,019 \\
52,20 \\
\end{array}$ & $\begin{array}{r}148,58 \\
0,025 \\
69,61 \\
182,14 \\
0,025 \\
69,69 \\
\end{array}$ & $\begin{array}{r}137,40 \\
0,021 \\
60,08 \\
173,04 \\
0,024 \\
69,16 \\
\end{array}$ & $\begin{array}{r}133,63 \\
0,020 \\
60,02 \\
154,21 \\
0,022 \\
66,35 \\
\end{array}$ \\
\hline $\begin{array}{l}\text { IRLANDA } \\
\text { Depósitos/PIB (\%) } \\
\text { Depósitos/Habitante (Mill.€) } \\
\text { Depósitos/Oficina (Mill.€) } \\
\text { Préstamos/PIB (\%) } \\
\text { Préstamos/Habitante (Mill.€) } \\
\text { Préstamos/Oficina (Mill.€) }\end{array}$ & $\begin{array}{r}109,36 \\
0,036 \\
149,38 \\
173,04 \\
0,057 \\
236,36\end{array}$ & $\begin{array}{r}113,91 \\
0,040 \\
167,74 \\
177,84 \\
0,062 \\
261,89\end{array}$ & $\begin{array}{r}118,78 \\
0,043 \\
189,57 \\
198,04 \\
0,072 \\
316,07\end{array}$ & $\begin{array}{r}131,49 \\
0,051 \\
227,63 \\
234,48 \\
0,091 \\
405,91\end{array}$ & $\begin{array}{r}150,57 \\
0,062 \\
276,78 \\
274,38 \\
0,112 \\
504,37\end{array}$ & $\begin{array}{r}169,41 \\
0,072 \\
270,22 \\
318,90 \\
0,136 \\
508,67\end{array}$ & $\begin{array}{r}174,50 \\
0,071 \\
339,68 \\
372,36 \\
0,151 \\
724,82\end{array}$ & $\begin{array}{r}172,11 \\
0,061 \\
221,67 \\
375,15 \\
0,134 \\
483,18\end{array}$ & $\begin{array}{r}108,61 \\
0,038 \\
143,69 \\
185,28 \\
0,064 \\
245,12\end{array}$ & $\begin{array}{r}101,67 \\
0,036 \\
145,52 \\
166,25 \\
0,056 \\
237,96\end{array}$ & $\begin{array}{r}105,19 \\
0,038 \\
156,92 \\
159,91 \\
0,057 \\
238,54\end{array}$ \\
\hline $\begin{array}{l}\text { PORTUGAL } \\
\text { Depósitos/PIB (\%) } \\
\text { Depósitos/Habitante (Mill.€) } \\
\text { Depósitos/Oficina (Mill.€) } \\
\text { Préstamos/PIB (\%) } \\
\text { Préstamos/Habitante (Mill.€) } \\
\text { Préstamos/Oficina (Mill.€) }\end{array}$ & $\begin{array}{r}108,23 \\
0,015 \\
28,34 \\
138,17 \\
0,019 \\
36,17 \\
\end{array}$ & $\begin{array}{r}109,59 \\
0,015 \\
29,02 \\
139,04 \\
0,019 \\
36,81 \\
\end{array}$ & $\begin{array}{r}95,63 \\
0,014 \\
26,46 \\
122,37 \\
0,017 \\
33,85 \\
\end{array}$ & $\begin{array}{r}96,67 \\
0,014 \\
27,38 \\
129,56 \\
0,019 \\
36,70 \\
\end{array}$ & $\begin{array}{r}97,35 \\
0,015 \\
27,77 \\
138,57 \\
0,021 \\
39,51 \\
\end{array}$ & $\begin{array}{r}100,07 \\
0,016 \\
27,88 \\
150,68 \\
0,024 \\
41,98 \\
\end{array}$ & $\begin{array}{r}126,68 \\
0,021 \\
33,82 \\
186,90 \\
0,030 \\
49,90 \\
\end{array}$ & $\begin{array}{r}129,64 \\
0,021 \\
33,32 \\
189,50 \\
0,030 \\
48,71 \\
\end{array}$ & $\begin{array}{r}133,38 \\
0,022 \\
34,87 \\
183,63 \\
0,030 \\
48,01 \\
\end{array}$ & $\begin{array}{r}142,90 \\
0,023 \\
37,47 \\
172,45 \\
0,028 \\
45,22 \\
\end{array}$ & $\begin{array}{r}151,97 \\
0,024 \\
39,99 \\
178,06 \\
0,028 \\
46,85 \\
\end{array}$ \\
\hline $\begin{array}{l}\text { CHIPRE } \\
\text { Depósitos/PIB (\%) } \\
\text { Depósitos/Habitante (Mill.€) } \\
\text { Depósitos/Oficina (Mill.€) } \\
\text { Préstamos/PIB (\%) } \\
\text { Préstamos/Habitante (Mill.€) } \\
\text { Préstamos/Oficina (Mill.€) }\end{array}$ & $\begin{array}{r}244,29 \\
0,038 \\
27,12 \\
172,46 \\
0,027 \\
19,15\end{array}$ & $\begin{array}{r}237,77 \\
0,038 \\
28,05 \\
170,75 \\
0,027 \\
20,14\end{array}$ & $\begin{array}{r}237,54 \\
0,041 \\
30,50 \\
172,44 \\
0,030 \\
22,14\end{array}$ & $\begin{array}{r}247,24 \\
0,045 \\
35,20 \\
278,77 \\
0,051 \\
39,69 \\
\end{array}$ & $\begin{array}{r}262,59 \\
0,051 \\
40,77 \\
297,51 \\
0,058 \\
46,19\end{array}$ & $\begin{array}{r}304,23 \\
0,062 \\
52,02 \\
329,27 \\
0,067 \\
56,30\end{array}$ & $\begin{array}{r}436,27 \\
0,094 \\
80,40 \\
383,02 \\
0,082 \\
70,58\end{array}$ & $\begin{array}{r}550,56 \\
0,113 \\
98,82 \\
444,11 \\
0,091 \\
79,71 \\
\end{array}$ & $\begin{array}{r}502,93 \\
0,104 \\
95,15 \\
431,01 \\
0,089 \\
81,55\end{array}$ & $\begin{array}{r}440,33 \\
0,092 \\
86,90 \\
437,36 \\
0,091 \\
86,32 \\
\end{array}$ & $\begin{array}{r}411,40 \\
0,085 \\
83,91 \\
457,38 \\
0,094 \\
93,28\end{array}$ \\
\hline
\end{tabular}


Tabla 6 (continuación)

Indicadores de operativa bancaria

(2002-2012)

\begin{tabular}{|l|r|r|r|r|r|r|r|r|r|r|r|}
\hline & $\mathbf{2 0 0 2}$ & $\mathbf{2 0 0 3}$ & $\mathbf{2 0 0 4}$ & $\mathbf{2 0 0 5}$ & $\mathbf{2 0 0 6}$ & $\mathbf{2 0 0 7}$ & $\mathbf{2 0 0 8}$ & $\mathbf{2 0 0 9}$ & $\mathbf{2 0 1 0}$ & $\mathbf{2 0 1 1}$ & $\mathbf{2 0 1 2}$ \\
\hline ISLANDIA & & & & & & & & & & & \\
Depósitos/PIB (\%) & 30,37 & 35,90 & 41,48 & 61,21 & 97,79 & 164,70 & 350,55 & 114,47 & 90,05 & 91,98 & 84,04 \\
Depósitos/Habitante (Mill.€) & 0,009 & 0,012 & 0,015 & 0,027 & 0,042 & 0,078 & 0,113 & 0,031 & 0,027 & 0,029 & 0,028 \\
Depósitos/Oficina (Mill.€) & 14,53 & 19,05 & 28,02 & 46,94 & 79,40 & 261,64 & 237,36 & 76,98 & n.d. & n.d. & n.d. \\
Préstamos/PIB (\%) & 64,38 & 78,61 & 139,45 & 194,28 & 344,47 & 350,14 & 725,87 & 148,96 & 123,93 & 120,28 & 118,24 \\
Préstamos/Habitante (Mill.€) & 0,021 & 0,026 & 0,051 & 0,085 & 0,149 & 0,166 & 0,234 & 0,041 & 0,037 & 0,038 & 0,039 \\
Préstamos/Oficina (Mill.€) & 30,80 & 41,72 & 94,21 & 148,97 & 279,69 & 556,21 & 491,51 & 100,17 & n.d. & n.d. & n.d. \\
\hline ESTADOS UNIDOS & & & & & & & & & & & \\
Depósitos/PIB (\%) & 40,28 & 49,28 & 55,91 & 56,67 & 59,00 & 66,18 & 75,03 & 74,61 & 69,93 & 76,04 & 71,49 \\
Depósitos/Habitante (Mill.€) & 0,016 & 0,017 & 0,019 & 0,020 & 0,022 & 0,023 & 0,025 & 0,025 & 0,025 & 0,027 & 0,029 \\
Depósitos/Oficina (Mill.€) & 52,70 & 55,68 & 59,57 & 62,90 & 66,95 & 70,47 & 74,74 & 76,26 & 78,88 & 85,20 & 91,49 \\
Préstamos/PIB (\%) & 35,32 & 43,48 & 50,53 & 52,12 & 53,57 & 60,94 & 63,85 & 57,01 & 52,80 & 54,40 & 50,70 \\
Préstamos/Habitante (Mill.€) & 0,014 & 0,015 & 0,017 & 0,018 & 0,020 & 0,021 & 0,021 & 0,019 & 0,019 & 0,019 & 0,020 \\
Préstamos/Oficina (Mill.€) & 46,24 & 49,13 & 53,83 & 57,84 & 60,79 & 64,89 & 63,61 & 58,28 & 59,56 & 60,95 & 64,88 \\
\hline
\end{tabular}

Nota: n.d. (no disponible).

Fuente: Elaboración propia a partir de los datos suministrados por "Banco Central Europeo", "Financial Supervisory Authority of Iceland", "Federal Deposit Insurance Corporation" y "Eurostat".

En cuanto a los datos de la actividad de depósitos y préstamos en relación a la red de oficinas, los resultados no permiten conclusiones comunes para los países considerados, pues en cuanto al volumen de depósitos captados por oficina, se puede destacar un incremento general, lo que demuestra el mayor ajuste de la red respecto a esta actividad de pasivo, muy acusado en Alemania, Portugal y Estados Unidos, pero una caída significativa en Irlanda, hasta 2011, e Islandia. El cuanto al volumen de préstamos por oficina, nos encontramos con una evolución estable en España (aunque con una cierta caída), de Grecia en 2012 (con aumentos anteriores), de Portugal durante el período de crisis; de aumento, por su parte, en Alemania (tras un ajuste previo de la ratio), de Chipre (espectacular) y de Estados Unidos (que aumenta tras algo de ajuste al principio de la crisis); y de caída importante, finalmente, en Irlanda e Islandia.

En definitiva pues, el importante ajuste al que han estado sometidos los sistemas bancarios de los países más afectados por la crisis financiera, y que han precisado ayudas públicas para su saneamiento, ha mostrado, en líneas generales, un proceso general de reducción en el número de entidades, de oficinas y de empleados, que se ha traducido además en un aumento en el grado de concentración, con ajustes en muchos de ellos de las ratios de servicio y de operativa bancaria, si bien los resultados no son totalmente homogéneos, situándose España en un lugar intermedio si tenemos en cuenta una valoración global de los indicadores, pues en sentido negativo destacan los correspondientes a Irlanda, Islandia y Grecia, superando nuestras cifras fundamentalmente a las de Estados Unidos, Alemania y Portugal.

En el futuro próximo, por tanto, si se mantiene la tendencia observada en los 
últimos años, las entidades bancarias españolas van a presentar un mayor grado de concentración en sus actividades, con un menor número de oficinas y de empleados, siendo aquellas de tamaño reducido, como lo han venido siendo hasta ahora.

\section{CONCLUSIONES}

El sector bancario español ha estado sometido a una crisis de gran envergadura a lo largo de los últimos años. Esta crisis, aunque tiene su punto de partida en el exterior, con la extensión de las hipotecas subprime norteamericanas fundamentalmente al viejo continente, no provocó inicialmente efectos significativos sobre las entidades españolas. Fue, sin duda, la crisis económica que acompañó a esa crisis financiera inicial, y la de la deuda soberana posterior, la que produjo un impacto mayor sobre nuestro sistema financiero en comparación con el de otros países de nuestro entorno.

En este contexto, nuestras autoridades reaccionaron a medida que el fenómeno de la crisis se iba haciendo cada vez más importante. Así, en un primer momento, se aplicaron medidas con un fuerte componente transitorio para que, sin alterar la estructura del sector bancario español, éste dispusiera de mecanismos adicionales de financiación para atender las demandas de crédito. El alargamiento de la crisis motivó, a continuación, la necesidad de aplicar medidas más intensas, de un carácter estructural más evidente, que el paso de los años ha mostrado una dudosa eficacia en algunas de ellas, como por ejemplo el impulso otorgado a la creación de Sistemas Institucionales de Protección para las entidades que se encontraban en situaciones delicadas.

Estos sistemas, en efecto, no han sido capaces por sí mismos de detener los problemas de las entidades que se constituyeron dentro de ellos, hasta tal punto de que fue necesario abordar cambios en profundidad en la estructura del funcionamiento de nuestras entidades.

No obstante, es cierto que algunas de las actuaciones previas al rescate bancario sufrido por nuestro país han servido para preparar el camino a los cambios posteriores, como fueron, entre otras, la creación del FROB en 2009, aunque modificadas sus competencias en normas siguientes, la reforma de los antiguos Fondos de Garantía de Depósitos, las mayores exigencias de provisiones (también ampliadas después), unos requisitos de capital más elevados, también objeto de cambios en una segunda fase, limitaciones a las retribuciones de los altos cargos, la regulación de los "bancos malos",...

En una segunda etapa, que se inicia con la solicitud del rescate bancario para las entidades españolas con mayores problemas, es cuando nuestras autoridades han aplicado reformas financieras más en profundidad, que han cambiado el mapa de uno de los grandes sectores bancarios de nuestro país, el de las cajas de ahorros, con su práctica desaparición, pues de las más de 45 entidades existentes 
antes de la crisis, en realidad sólo quedan 2 (Caixa Pollença y Caixa Ontinyent), habiendo el resto formado grupos bancarios, cuya actividad financiera es desarrollada por un banco. También el sector de las cooperativas de crédito ha conocido una fuerte reestructuración, a través de la realización de fusiones o la constitución de SIP, dibujando un panorama parcialmente diferente al que tenía el sector antes de la crisis.

Esta segunda etapa ha conocido los cambios más drásticos en nuestro sistema financiero, en parte por las exigencias derivadas del acceso al rescate. Y, así, destacan la puesta en funcionamiento del "banco malo", los planes para la actuación temprana, la reestructuración y la resolución de entidades con problemas, el aumento de las competencias sancionadoras del Banco de España, el fortalecimiento del FROB, la nueva normativa para las cajas de ahorros, las mayores exigencias de provisiones para las exposiciones al sector inmobiliario,...

Finalizada la etapa más intensa de crisis, el sistema bancario español se caracteriza por la creación de grupos bancarios de mayor tamaño, lo que ha aumentado el grado de concentración del sector; por mayores exigencias de recursos propios y de provisiones para su fortalecimiento; por un mayor seguimiento de los riesgos asumidos por las entidades y de las exigencias establecidas a partir de un nuevo modelo de supervisión del Banco de España; por el establecimiento de un régimen de incompatibilidades para los altos cargos más exigente, tratando de separar la actividad pública de la financiera; por una vuelta al origen de las cajas de ahorros, al centrar sus operaciones en sus correspondientes ámbitos geográficos;... Todos ellos son algunos de los cambios y de la nueva realidad que va a conformar nuestro sistema bancario para los próximos años.

Además, por último, estas modificaciones se han producido en forma más o menos similar en otros países cuyos sistemas bancarios han precisado de ayudas públicas para su saneamiento, pues la tónica general ha sido el ajuste en el número de entidades, de oficinas y de empleados, el incremento en el grado de concentración y unas ratios marcadas, en gran medida, por esos ajustes y por la evolución de sus correspondientes niveles de actividad económica. Y todo ello, refiriéndonos al marco de la UE, con los cambios necesarios que habrá que llevar a cabo en los países de esta área, para alcanzar una Unión Bancaria Europea de acuerdo con los principios diseñados.

\section{REFERENCIAS BIBLIOGRÁFICAS}

AMERICAN BANKERS' ASSOCIATION (2002-2012): Banking Industry Statistics. Disponible en: http://www.aba.com/Tools/Economic/Pages/Bankinglnfo.aspx. [Último acceso: Febrero de 2014]. 
BANCO DE ESPAÑA (2000-2012): Memoria de la supervisión bancaria en España. Madrid. Disponible en: http://www.bde.es/bde/es/secciones/informes/Publicaciones _an/Memoria_de_la_Su/anoactual/. [Último acceso: Febrero de 2014].

BANCO DE ESPAÑA (2011): Nota sobre el proceso de reestructuración de las cajas de ahorros. Situación a julio de 2011. Madrid. Disponible en: http://www.bde.es/f/webbde/GAP/Secciones/SalaPrensa/InformacionInteres/Reestru cturacionSectorFinanciero/Ficheros/es/notareformacajas130711.pdf. [Último acceso: Febrero de 2014].

BANCO DE ESPAÑA (2012): Resultados de la evaluación independiente del sector bancario español. Madrid. Disponible en: http://www.bde.es/f/webbde/GAP/ Secciones/SalaPrensa/InformacionInteres/ReestructuracionSectorFinanciero/Fichero s/es/presentacion210612.pdf. [Último acceso: Febrero de 2014].

CALVO, A. y MARTÍN DE VIDALES, I. (2014). "Crisis financiera: impacto y tratamiento en España, Alemania, Irlanda, Islandia y Estados Unidos". Ola Financiera, 17, eneroabril, pp. 79-115.

CALVO, A. y MINGORANCE, A.C. (2012). "Por una reforma ética del sistema financiero". Revista de Fomento Social, 266, abril-junio, pp. 277-305.

CLIMENT, S. (2012). "La caída de las cajas de ahorros españolas. Cuestión de rentabilidad, tamaño y estructura de propiedad”. Estudios de Economía Aplicada, 30 (2), pp. $1-26$.

CONFEDERACIÓN ESPAÑOLA DE CAJAS DE AHORROS (2013): Proceso de reestructuración sector cajas de ahorros. Informe de avances. Disponible en: http://www.cajasdeahorros.es/pdfs/informe.pdf. [Último acceso: Febrero de 2014].

CUERVO, Á.; CALVO, A.; PAREJO, J.A. y RODRÍGUEZ, L. (2012). Manual de Sistema Financiero Español. Barcelona: Editorial Ariel Economía, 24a edición.

DEUTSCHE BUNDESBANK (2009). "Package of measures to stabilize the financial system". Annual Report 2008, p. 85.

EUROPEAN CENTRAL BANK (2002-2012): Structural Financial Indicators. Disponible en: $\quad h t t p: / / s d w . e c b . e u r o p a . e u / b r o w s e S e l e c t i o n . d o ? D A T A S E T=0 \& s f l 2=4 \& R E F$ $A R E A={ }^{*} E U \& s f \mid 3=4 \& S S I$ INDICATOR=N10\&node=9484387. [Último acceso: Febrero de 2014].

EUROPEAN COMMISSION (2012): Financial assistance programme for the recapitalisation of financial institutions in Spain. First review. Disponible en: http://www.bde.es/ f/webbde/GAP/Secciones/SalaPrensa/InformacionInteres/ReestructuracionSectorFin anciero/Archivo/Ficheros/comision_informeevaluacion112012en.pdf. [Último acceso: Febrero de 2014].

EUROPEAN COMMISSION (2013): Financial assistance programme for the recapitalisation of financial institutions in Spain. Second review. Disponible en: http://www.bde.es/f/webbde/GAP/Secciones/SalaPrensa/Informacionlnteres/Reestruc turacionSectorFinanciero/Archivo/Ficheros/comision_informeevaluacion032013en.pdf[Últ imo acceso: Febrero de 2014].

EUROPEAN COMMISSION (2013): Financial assistance programme for the recapitalisation of financial institutions in Spain. Third review. Disponible en: http://www.bde.es/f/webbde/GAP/Secciones/SalaPrensa/InformacionInteres/Ree structuracionSectorFinanciero/Arc/comision_informeevaluacion062013en.pdf. [Último acceso: Febrero de 2014].

EUROPEAN COMMISSION (2013): Financial assistance programme for the recapitalisation of financial institutions in Spain. Fourth review. Disponible 
en: http://www.bde.es/f/webbde/GAP/Secciones/SalaPrensa/InformacionInteres/PlanEur opeoRecapitalizacionBancaria/Ficheros/comision_informeevaluacion092013en.pdf.

[Último acceso: Febrero de 2014].

EUROPEAN COMMISSION (2014): Financial assistance programme for the recapitalisation of financial institutions in Spain. Fifth review. Disponible en: http://www.bde.es/f/webbde/GAP/Secciones/SalaPrensa/InformacionInteres/Ree structuracionSectorFinanciero/Arc/Fic/en/comision_informeevaluacion012014en.pdf. [Último acceso: Febrero de 2014].

EUROSTAT (2002-2012): Statistics. Disponible en: http://epp.eurostat.ec.europa.eu/ portal/page/portal/statistics/themes./. [Último acceso: Febrero de 2014].

FEDERAL DEPOSIT INSURANCE CORPORATION (2002-2012): Statistics at a Glance. Disponible en: http://www.fdic.gov/bank/statistical/stats/. [Último acceso: Febrero de 2014].

FINANCIAL SUPERVISORY AUTHORITY OF ICELAND (2002-2012): Annual Report. Reykjavik. Disponible en: http://en.fme.is/published-material/annual-reports/. [Último acceso: Febrero de 2014].

FINANCIAL SUPERVISORY AUTHORITY OF ICELAND (2002-2012): Key Figures from Annual Accounts. Reykjavik. Disponible en: http://en.fme.is/published-material/statistical-information/. [Último acceso: Febrero de 2014].

INTERNATIONAL MONETARY FUND (2012): Spain: Financial Stability Assessment. Disponible en: Washington. http://www.imf.org/external/pubs/ft/scr/2012/cr12137.pdf. [Último acceso: Febrero de 2014].

MINISTERIO DE ASUNTOS EXTERIORES Y DE COOPERACIÓN (2012): Memorando de Entendimiento sobre condiciones de política sectorial financiera. Madrid. Disponible en: http://www.mineco.gob.es/stfls/mineco/prensa/ficheros/noticias/2012/120720_ MOU_espanyol_2_rubrica_MECC_VVV.pdf. [Último acceso: Febrero de 2014].

OLIVER WYMAN (2012a): Bank of Spain stress testing exercise. Madrid. Disponible en: http://www.bde.es/f/webbde/GAP/Secciones/SalaPrensa/InformacionInteres/ReestructuracionSectorFinanciero/Ficheros/en/informe_oliverwymane.pdf. [Último acceso: Febrero de 2014].

OLIVER WYMAN (2012b): Asset quality review and bottom-up stress test exercise. Madrid. Disponible en: http://www.bde.es/f/webbde/SSICOM/20120928/informe_ ow280912e.pdf. [Último acceso: Febrero de 2014].

PALOMO, R.J. y SANCHÍS, J.R. (2008). "Un análisis del crédito cooperativo en España: situación actual, expansión territorial y proyección estratégica”. Estudios de Economía Aplicada, 26 (1), pp. 89-132.

ROLAND BERGER (2012): Stress testing spanish banks. Madrid. Disponible en: http://www.bde.es/f/webbde/GAP/Secciones/SalaPrensa/Informacionlnteres/ReestructuracionSectorFinanciero/Ficheros/en/informe_rolandbergere.pdf. [Último acceso: Febrero de 2014].

SERVICIO DE ESTUDIOS DE LA CAIXA (2008). "Convulsión en el sistema financiero". Informe Mensual, 317, pp.10-13.

SOCIEDAD DE GESTIÓN DE ACTIVOS PROCEDENTES DE LA REESTRUCTURACIÓN BANCARIA (2013): Informe de actividad. Madrid. Disponible en: http://www.sareb.es/es-es/accionistas-e-inversores/Documents/Informe\%20Primer\% 20Semestre\%202013\%20Sareb.pdf. [Último acceso: Febrero de 2014]. 
SUBDIRECCIÓN GENERAL DE ASUNTOS ECONÓMICOS Y FINANCIEROS DE LA UNIÓN EUROPEA (2009). "La respuesta europea a la crisis financiera y económica". Boletín Económico de ICE, 2.957, pp. 3-22.

TORIBIO, J.J. (2010). "Crisis financiera y crisis moral", Conferencia pronunciada en la Jornada sobre La dimensión moral de la crisis económica, 23-24 de junio. Universidad CEU San Pablo.

UNIÓN EUROPEA (2013). Informe General 2013, capítulo 2 (Hacia una Unión Económica, Fiscal y Bancaria). Bruselas.

UNIÓN NACIONAL DE COOPERATIVAS DE CRÉDITO (2013): Anuario. Madrid. Disponible en: http://www.unacc.com/inicio/Publicaciones/Anuario.aspx. [Último acceso: Febrero de 2014]. 